\title{
Cracking Down on Inhibition: Selective Removal of GABAergic Interneurons from Hippocampal Networks
}

\author{
Flavia Antonucci, ${ }^{1,2 *}$ Alán Alpár, ${ }^{3 *}$ Johannes Kacza, ${ }^{4}$ Matteo Caleo, ${ }^{5}$ Claudia Verderio, ${ }^{1}$ Alice Giani, ${ }^{1}$ Henrik Martens, ${ }^{6}$ \\ Farrukh A. Chaudhry, ${ }^{7}$ Manuela Allegra, ${ }^{5}$ Jens Grosche, ${ }^{8}$ Dominik Michalski, ${ }^{9}$ Christian Erck, ${ }^{6}$ Anke Hoffmann, ${ }^{4}$ \\ Tibor Harkany, ${ }^{3,10}$ Michela Matteoli, ${ }^{1,11}$ and Wolfgang Härtig ${ }^{8}$ \\ ${ }^{1}$ Department of Medical Pharmacology, CNR Institute of Neuroscience, Università di Milano and ${ }^{2}$ Fondazione Filarete, I-20129 Milan, Italy, ${ }^{3}$ Division of Molecular \\ Neurobiology, Department of Medical Biochemistry \& Biophysics, Karolinska Institutet, S-17177 Stockholm, Sweden, ${ }^{4}$ Institute of Veterinary Anatomy, University \\ of Leipzig, D-04103 Leipzig, Germany, ${ }^{5} \mathrm{CNR}$ Institute of Neuroscience, I-51600 Pisa, Italy, ${ }^{6}$ Synaptic Systems GmbH, D-37079 Göttingen, Germany, ${ }^{7}$ The \\ Biotechnology Centre of Oslo \& Centre for Molecular Biology and Neuroscience, University of Oslo, N-0317 Oslo, Norway, ${ }^{8}$ Paul Flechsig Institute for Brain Research, \\ University of Leipzig, D-04109 Leipzig, Germany, ${ }^{9}$ Department of Neurology, University of Leipzig, D-04103 Leipzig, Germany, ${ }^{10}$ European Neuroscience Institute, \\ University of Aberdeen, Aberdeen AB25 2ZD, United Kingdom, and ${ }^{11}$ Instituto Clinico Humanitas, IRCCS, Rozzano, I-20089 Milan, Italy
}

Inhibitory (GABAergic) interneurons entrain assemblies of excitatory principal neurons to orchestrate information processing in the hippocampus. Disrupting the dynamic recruitment as well as the temporally precise activity of interneurons in hippocampal circuitries can manifest in epileptiform seizures, and impact specific behavioral traits. Despite the importance of GABAergic interneurons during information encoding in the brain, experimental tools to selectively manipulate GABAergic neurotransmission are limited. Here, we report the selective elimination of GABAergic interneurons by a ribosome inactivation approach through delivery of saporin-conjugated anti-vesicular GABA transporter antibodies (SAVAs) in vitro as well as in the mouse and rat hippocampus in vivo. We demonstrate the selective loss of GABAergic- but not glutamatergic - synapses, reduced GABA release, and a shift in excitation/inhibition balance in mixed cultures of hippocampal neurons exposed to SAVAs. We also show the focal and indiscriminate loss of calbindin ${ }^{+}$, calretinin ${ }^{+}$, parvalbumin/system A transporter $1^{+}$, somatostatin $^{+}$, vesicular glutamate transporter 3 (VGLUT3)/cholecystokinin/CB ${ }_{1}$ cannabinoid receptor ${ }^{+}$and neuropeptide $\mathrm{Y}^{+}$local-circuit interneurons upon SAVA microlesions to the CA1 subfield of the rodent hippocampus, with interneuron debris phagocytosed by infiltrating microglia. SAVA microlesions did not affect VGLUT1 ${ }^{+}$excitatory afferents. Yet SAVA-induced rearrangement of the hippocampal circuitry triggered network hyperexcitability associated with the progressive loss of CA1 pyramidal cells and the dispersion of dentate granule cells. Overall, our data identify SAVAs as an effective tool to eliminate GABAergic neurons from neuronal circuits underpinning high-order behaviors and cognition, and whose manipulation can recapitulate pathogenic cascades of epilepsy and other neuropsychiatric illnesses.

\section{Introduction}

Local-circuit, GABA-releasing inhibitory interneurons in the hippocampus and cerebral cortex regulate global firing rates by coordinating the temporally precise activity of excitatory neuron

Received June 1, 2011; revised Dec. 7, 2011; accepted Dec. 14, 2011.

Author contributions: A.A., C.V., T.H., M.M., and W.H. designed research; F.A., A.A., J.K., M.C., C.V., A.G., H.M., D.M., M.A., J.G., A.H., and W.H. performed research; M.C., F.A.C., H.M., and C.E. contributed unpublished reagents/ analytic tools; F.A., M.C., J.G., and W.H. analyzed data; A.A., T.H., M.M., and W.H. wrote the paper.

This work was supported by the European Union $7^{\text {th }}$ Framework Program Grants HEALTH-F2-2009-241498 (EUROSPIN, M.M., H.M.) and HEALTH-F2-2007-201159 (MEMOLOAD, T.H.), the Scottish Universities Life Science Alliance (A.A., T.H.), National Institutes of Health (DA023214, T.H.), the Swedish Research Council (T.H.), Compagnia di San Paolo, Torino, Italy (M.M., M.C.), PRIN 20082008 T4ZCNL (M.M.), and Cariplo 2998 -3184 (M.M.). We thank Jean-Marc Fritschy, Wolfgang H. Oertel, Hiroyuki Hioki, Michele Solimena and Masahiko Watanabe for antibodies. The technical assistance provided by Matthias Böddener, Ute Bauer, Marita Heindl, Gabriele Lindner and Orsolya Penz is gratefully acknowledged.

*F.A. and A.A. contributed equally to this work.

The authors declare no competing financial interests.

Correspondence should be addressed to either of the following: Tibor Harkany, Division of Molecular Neurobiology, Department of Medical Biochemistry \& Biophysics, Scheeles väg 1:A1, Karolinska Institutet, S-17177 Stockholm, Sweden, E-mail: Tibor.Harkany@ki.se; or Michela Matteoli, Department of Medical Pharmacology, CNR Institute of Neuroscience, University of Milan, I-20129 Milan, Italy, E-mail: michela.matteoli@unimi.it.

A. Alpár's permanent address: Department of Anatomy, Histology and Embryology, Semmelweis University, Túzoltó u. 58, H-1094 Budapest, Hungary.

DOI:10.1523/JNEUROSCI.2720-11.2012

Copyright $\odot 2012$ the authors $\quad 0270-6474 / 12 / 321989-13 \$ 15.00 / 0$ ensembles along short time scales (Freund and Buzsáki, 1996; Turner et al., 1998; McBain and Fisahn, 2001; Somogyi and Klausberger, 2005; Bartos et al., 2007; Buzsáki et al., 2007; Ascoli et al., 2008). The coordinated interplay of structurally and functionally diverse interneurons in the hippocampus is essential for the dynamic processing of information and allows adaptive experience-dependent modifications to network connectivity (Davies et al., 1998; Bartos et al., 2007; Buzsáki et al., 2007; Cardin et al., 2009; Murray et al., 2011). The molecular diversity of pallial GABAergic interneurons is transcriptionally encoded to define their migratory routes, neurochemical make-up and network contributions (Pleasure et al., 2000; Anderson et al., 2002; Tricoire et al., 2011). GABAergic interneurons directly impact their microenvironment by presenting cues for cell migration and directional axonal growth (Manent et al., 2005; López-Bendito et al., 2006). The early formation of GABAergic synapses_-preceding glutamatergic ones (Khazipov et al., 2001)—and their excitatory output are essential to drive the activity-dependent wiring of neuronal networks (Ben-Ari, 2002; Ben-Ari et al., 2007).

Impaired GABAergic neurotransmission has been implicated in the molecular pathogenesis of neurological and neuropsychi- 
atric illnesses (Davies et al., 1998; Costa et al., 2004; Di Cristo, 2007; Sun et al., 2009), most notably epilepsy (Mody et al., 1992; Ben-Ari, 2001; Cossart et al., 2005; Katona and Freund, 2008). In the epileptic hippocampus, recurrent seizures induce extensive modifications to neuronal circuitries amassing to principal cell loss and compensatory granule cell dispersion (Ben-Ari, 2001; Antonucci et al., 2008; Pitkänen and Lukasiuk, 2009). Because of the inherent role of GABAergic interneurons as "gatekeepers" of neuronal circuits, establishment of experimental strategies amenable to efficiently manipulate GABAergic neurotransmission in living tissues is invaluable to broaden present understanding of the (dys)functions of GABAergic neurons.

The fidelity and specificity of GABAergic neurotransmission are controlled by specific carrier systems, tuning neurotransmitter release from inhibitory terminals. The vesicular GABA transporter [VGAT/vesicular inhibitory amino acid transporter (VIAAT)] is one such critical presynaptic component loading GABA into synaptic vesicles (McIntire et al., 1997; Sagné et al., 1997; Chaudhry et al., 1998). VGAT is a ubiquitous molecular constituent of GABAergic presynapses (Chaudhry et al., 1998) whose $\mathrm{C}$ terminus (VGAT-C) becomes transiently exposed at the presynaptic surface during neurotransmitter release (Martens et al., 2008). Therefore, we hypothesized that VGAT may be a potential molecular target suited to specifically disrupt inhibitory neurotransmission in hippocampal neuronal circuitries. Here, we generated saporin-conjugated anti-VGAT-C antibodies (SAVAs), analogous to other saporin-based targeting toxins (Wiley et al., 1995; Wrenn et al., 1996; Wiley and Lappi, 1997), to eliminate GABAergic interneurons from the murine hippocampus. We used a multiparametric approach to demonstrate that SAVAs efficaciously disrupt GABAergic neurotransmission followed by structural rearrangement of the lesioned hippocampal circuitry, manifesting as spontaneous neuronal hyperexcitability. Thus, our data provide a platform for the selective manipulation of both localcircuit and projection GABA cells in the nervous system.

\section{Materials and Methods}

Animals. All procedures involving animals were performed according to the guidelines of the local Animal Care and Use Committee and the Regierungspräsidium Leipzig (TVV 05/08), and the Institutional Animal Care and Use Committee of the CNR Institute of Neuroscience. C57BL/6N mice $(n=50,8-24$ weeks of age, $24-32 \mathrm{~g})$ or Wistar rats $(n=$ $16,300-350 \mathrm{~g}$ ) of both sexes were from our own colonies at the University of Leipzig. Mice were housed on a $12 \mathrm{~h}$ light/dark cycle with food and water available ad libitum. In accordance with the relevant European Communities Council Directive (86/609/EEC), efforts were made to reduce the number of animals used and minimize their suffering.

Immunotoxin preparation and quality control. Purified rabbit antiVGAT-C (1 mg/production cycle; Synaptic Systems) was dialyzed against PBS (50 mu, pH 7.4) containing $10 \mathrm{~mm}$ EDTA, concentrated to $1 \mathrm{mg} / \mathrm{ml}$ by applying a Vivaspin concentrator $(30 \mathrm{kDa}$ molecular weight cutoff; Vivascience/Sigma-Aldrich), and reduced (1 mg) by dithiothreitol to a final concentration of $20 \mathrm{~mm}$ for $30 \mathrm{~min}$. Lyophilized saporin extracted from Saponaria officinalis seeds (Sigma-Aldrich) was reconstituted with water $(2 \mathrm{mg} / \mathrm{ml})$, and dialyzed against PBS, pH 7.4. Eighty microliters of freshly prepared sulfosuccinimidyl 6-[ $\alpha$-methyl- $\alpha$-(pyridyldithio) toluamido]hexanoate (sulfo-LC-SMPT, final concentration: $2 \mathrm{mg} / \mathrm{ml}$; Thermo Scientific) were added to $2 \mathrm{mg}$ of saporin and incubated for $2 \mathrm{~h}$ in a head-over-tail rotator. Freshly reduced antibody and saporin coupled to Sulfo-LC-SMPT were separately equilibrated to PBS/10 mM EDTA by applying a $5 \mathrm{ml} \mathrm{ZEBA} \mathrm{Spin} 7 \mathrm{kDa}$ molar weight cutoff desalting column (Thermo Scientific). Antibodies and saporin were combined, and absorption at $343 \mathrm{~nm}$ was measured immediately and after overnight incubation at room temperature. The ensuing SAVA conjugate was affinity-purified using VGAT-C immunogen immobilized on sulfo-linkSepharose (Thermo Scientific) to remove free saporin. The purity of this immunotoxin was analyzed after nonreducing SDS-PAGE and Coomassie staining (Syrový and Hodný, 1991). Similar to other neurotoxins incorporating the ribosome-inactivating toxin saporin, SAVAs were found sensitive to repeated freeze/thaw cycles. SAVAs withstood lyophilization and reconstitution without significant loss of their biological activity. We found that small aliquots $(20-100 \mu l$ each) should be kept at $-80 /-150^{\circ} \mathrm{C}$ for long-term storage, and on ice during experimentation to minimize the undesired loss of this immunoreagent's biological activity. SAVAs were aliquoted $(100 \mu \mathrm{l})$ at a stock concentration of $0.6-0.7$ $\mathrm{mg} / \mathrm{ml}$ in PBS to which $4-5 \mathrm{mg} / \mathrm{ml} \mathrm{BSA}$ (Sigma-Aldrich) had been added, and stored at $-80^{\circ} \mathrm{C}$. Aliquots were thawed and kept on ice throughout the experiments.

In vitro toxin exposure. Primary neuronal cultures were prepared from the hippocampi of Sprague Dawley rat fetuses harvested on day 18 of pregnancy (Charles River Italica) (Pozzi et al., 2008). Dissociated cells were plated at densities ranging from 10,000 to $20,000 \mathrm{cells} / \mathrm{cm}^{2}$ onto poly-L-lysine-coated glass coverslips. Primary cultures were maintained in Neurobasal medium (Invitrogen) with B27 supplement and antibiotics, $2 \mathrm{~mm}$ glutamine, and glutamate (neuronal medium; all from Invitrogen). Neurons at 10-12 DIV were used to evaluate the lesion efficacy of SAVAs. One to $3 \mathrm{~d}$ after incubation with SAVAs $(0.5 \mathrm{mg} / \mathrm{ml}$, single exposure), neurons on coverslips were processed for further analyses.

Immunocytochemistry. After a brief wash in ice-cold phosphate buffer (0.1 м PB, pH 7.4), neurons were fixed with $4 \%$ paraformaldehyde (PFA) in $\mathrm{PB}$ for $20 \mathrm{~min}$. Select combinations of the following primary antibodies were used: human sera from patients affected by Stiff-man syndrome and specifically recognizing the $65 \mathrm{kDa}$ isoform of glutamic acid decarboxylase [GAD65 (1:100); gift from Dr. M. Solimena, Dresden, Germany], mouse anti-MAP2 (1:500, Immunological Sciences), guinea pig anti-vesicular glutamate transporter 1 (1:200, VGLUT1; Synaptic Systems) and mouse anti-gephyrin (1:500, Synaptic Systems). Primary antibodies were visualized by Alexa Fluor488-tagged anti-human IgG (1: 100, Invitrogen), Alexa Fluor568-conjugated anti-mouse IgG (1:200, Invitrogen) or Cy5-anti-guinea pig IgG (1:200, Jackson ImmunoResearch). Cellular nuclei were counterstained with 4',6-diamidino-2phenylindole (DAPI; Serva). SAVA-induced reduction in the density of GAD $65^{+}$or VGLUT1 ${ }^{+}$synapses and perikarya was analyzed by randomly selecting three fields of view acquired at $40 \times$ primary magnification (Zeiss LSM710) from $n=6$ coverslips in experiments performed in triplicate by investigators blind to the type of experimental manipulation. Synaptic density was determined by calculating the number of $\mathrm{GAD} 5^{+}$or VGLUT1 ${ }^{+}$puncta in fields of fixed dimensions. The detection threshold was set to 2.5 -fold the level of background fluorescence referring to diffuse fluorescence within dendritic shafts. The minimum puncta size was set at 3 pixel $\left(0,027 \mu \mathrm{m}^{2}\right.$; ImageJ). SAVA-induced cell death was calculated upon simultaneous imaging of GAD $65^{+} / \mathrm{DAPI}^{+}$ neurons. Condensed and fragmented nuclei of irregular shape (see Fig. $2 B$ ) surrounded by GAD $65^{+}$cytoplasm fragments were considered as morphological indices of neuronal injury (the threshold for the size of an intact nucleus was $\geq 15 \mu \mathrm{m}$; ImageJ plug-in).

Electrophysiology. Whole-cell patch-clamp recordings were performed in 12 DIV neurons by using an Axopatch 200B amplifier (Molecular Devices). Recordings were performed in the voltage-clamp mode. Currents were sampled at $2 \mathrm{kHz}$ and filtered at $2-5 \mathrm{kHz}$. External solution (Krebs-Ringer's-HEPES) consisted of (in $\mathrm{mM}$ ): $125 \mathrm{NaCl}, 5 \mathrm{KCl}, 1.2$ $\mathrm{MgSO}_{4}, 1.2 \mathrm{KH}_{2} \mathrm{PO}_{4}, 2 \mathrm{CaCl}_{2}, 6$ glucose, and 25 HEPES-NaOH, pH 7.4. Miniature (m) EPSCs and mIPSCs were recorded in the presence of $1 \mu \mathrm{M}$ tetrodotoxin (TTX; Tocris Bioscience). Recording pipettes were pulled from capillary glass (World Precision Instruments) using a two stage puller (Narishige), and had tip resistances of 3-5 $\mathrm{M} \Omega$ when filled with intracellular solution (in mM): $130 \mathrm{~K}$-gluconate, $10 \mathrm{KCl}, 1 \mathrm{EGTA}, 10$ HEPES, $2 \mathrm{MgCl}_{2}$, $4 \mathrm{Mg}$-ATP, and 0.3 Tris-GTP. Voltage-clamp recordings were performed at holding potentials of $-70 \mathrm{mV}$ and $+10 \mathrm{mV}$ for mEPSCs and mIPSCs, respectively. Recordings were performed at room temperature. Data were analyzed off-line (pClamp-10 software, Molecular Devices). Events that had exceeded two times the SD of the baseline noise were considered as mEPSCs/mIPSCs and included in our analyses. 
$\mathrm{Ca}^{2+}$-imaging. Hippocampal cultures (13 DIV) were loaded with the ratiometric $\mathrm{Ca}^{2+}$ dye Fura-2 pentacetoxy methylester $(2 \mu \mathrm{M}$; SigmaAldrich) in Krebs-Ringer solution at $37^{\circ} \mathrm{C}$ for $30 \mathrm{~min}$ (Verderio et al., 2004), washed in the same solution, and transferred to the recording chamber of an inverted microscope (Zeiss Axiovert 100). $\mathrm{Ca}^{2+}$ imaging was performed by using a Polychrome IV integrated multi-wavelength illumination system (TILL Photonics) as monochromatizing device and light source coupled to a PCO Super VGA SensiCam (Molecular Devices) camera. Fura-2 fluorescence images were analyzed with TILLvision software (TILL Photonics). After excitation at 340 and $380 \mathrm{~nm}$ wavelengths, emitted light was acquired at $505 \mathrm{~nm}$ at a rate of $1-4 \mathrm{~Hz}$. Temporal $\mathrm{Ca}^{2+}$ intensity profiles (expressed as F340/380 fluorescence ratio) were calculated in discrete areas of interest from image sequences. "Ratio changes" indicate the amplitude of peak $\mathrm{Ca}^{2+}$ responses. In addition to analyzing the frequency of intracellular $\mathrm{Ca}^{2+}$ oscillations, the percentage of neurons that failed to retain Fura-2 $(1 \mathrm{kDa})$ due to the SAVA-induced increase in membrane permeability (see Fig. $2 C$ ) was also determined. We interpreted these results as an indication of on-going cell death (Verderio and Matteoli, 2001; Verderio et al., 2001).

Stereotaxic injections. Mice were anesthetized with an intraperitoneal injection of either etomidate (Hypnomidate; $33 \mathrm{mg} / \mathrm{kg}$ body weight; Janssen-Cilag) or tribomethanol (Avertin, Sigma-Aldrich) (Antonucci et al., 2008). Local analgesia of the skull was achieved via subcutaneous administration of lidocaine hydrochloride (Licain; $1 \% ; 17.5 \mathrm{mg} / \mathrm{kg}$ body weight; DeltaSelect). Mice received injections of $2 \mu \mathrm{l}$ of SAVAs $(\sim 0.5$ $\mathrm{mg} / \mathrm{ml} \mathrm{PBS})$ or unconjugated rabbit anti-VGAT-C IgG as control $(n=5)$ into the left dorsal hippocampus at the coordinates: anterior-posterior $(\mathrm{AP})=-1.5 \mathrm{~mm}$ (relative to bregma), lateral $(\mathrm{L})=1.8 \mathrm{~mm}$ and dorsoventral $(D V)=1.6 \mathrm{~mm}$ (Paxinos and Franklin, 2001). In an independent subset of animals, bilateral SAVA injections $(500 \mathrm{nl}, 2 \mu \mathrm{g} / \mu \mathrm{l})$ were made at the following coordinates (in $\mathrm{mm}$ with respect to bregma) (Paxinos and Franklin, 2001): $\mathrm{AP}=-2.0 \mathrm{~mm}, \mathrm{~L}=1.5 \mathrm{~mm}, \mathrm{DV}=1.7 \mathrm{~mm}$ below dura ( $n=5$ mice/group). Survival times were either $12 \mathrm{~d}$ or 10 weeks postlesion.

Rats were anesthetized with a mixture of ketamine ( $30 \mathrm{mg} / \mathrm{kg}$; Ketavet, Pfizer) and xylazine (15 mg/kg; Rompun, Bayer HealthCare). Local analgesia of the skull was sustained with a subcutaneous injection of lidocaine hydrochloride (Licain; 1\%). After mounting their heads in a stereotaxic frame, rats received an injection of $5 \mu$ l of SAVAs $(\sim 0.5$ $\mathrm{mg} / \mathrm{ml} \mathrm{PBS} ; 1 \mu \mathrm{l} / \mathrm{min}$ infusion speed) in the left hippocampus at coordinates: $\mathrm{AP}=4.3 \mathrm{~mm}$ (relative to bregma), $\mathrm{L}=3.5 \mathrm{~mm}$ and $\mathrm{DV}=$ $3.0 \mathrm{~mm}$ (Paxinos and Watson, 1986). A $12 \mathrm{~d}$ postlesion survival period was used. In control experiments, the same coordinates were used for the injection of unconjugated rabbit anti-VGAT-C (unc-Ab) IgG into the hippocampi.

Mice and rats tolerated the SAVA doses ( $1-5 \mu \mathrm{g} /$ injection, depending on the animal species) generally well, although premature deaths have occasionally been recorded [mice: 6 of 44 after SAVA infusion (13.6\%); rats: 2 of 16 upon SAVA infusion (12.5\%)]. The prevalence of lethality did not differ between the control [mice: 2 of $16(12.5 \%)$ ] and SAVAlesioned groups.

Placement of hippocampal electrodes and EEG recordings. Mice $(n=5$ SAVA, $n=2$ unc-Ab, and $n=3$ control) were implanted with a bipolar electrode inserted into one of the two injected hippocampi $9 \mathrm{~d}$ after bilateral injections. The bipolar electrode was made of two twisted enamel-insulated nichromes $(120 \mu \mathrm{m})$. A ground electrode was placed over the cerebellum. Electrodes were connected to a multi-pin socket and secured to the skull by acrylic dental cement. Animals were allowed to recover $2 \mathrm{~d}$ after surgery. EEG recordings were performed in freely moving-mice using a digital acquisition computer-based system. Each animal was recorded for $1 \mathrm{~h}$ daily during the light period. Before initiating an EEG recording session, a period of $1 \mathrm{~h}$ was allowed for the animals to habituate to the test cage. Hippocampal EEG signals were amplified $(10,000$-fold), bandpass filtered $(0.3-30 \mathrm{~Hz})$, digitized (National Instruments card), and transferred to a computer for storage and analysis. Data analysis was performed blind to the experimental condition. Detection of high-amplitude isolated events was performed with custom software written in LabView (National Instruments) (Antonucci et al., 2008). The program identified alterations in the EEG trace using a voltage threshold (see Fig. 7A; set to 4.5 times the SD of the EEG signal; horizontal line). The frequency of EEG alterations was determined for each recording session (Antonucci et al., 2008). These were compared with neocortical EEG records to verify selective hippocampal involvement. Animals were transcardially perfused after the EEG recordings and their hippocampi processed to verify the loss of GABAergic (parvalbumin ${ }^{+}$) interneurons in the CA1 subfield (data not shown).

Tissue preparation. Twelve days or 10 weeks after unilateral injection, the animals were transcardially perfused with PFA and $0.1 \%$ glutaraldehyde (GA) in PB. Subsequently, brains were postfixed in PFA in PB and cryoprotected by equilibration with $30 \%$ sucrose in $0.1 \mathrm{M}$ PB. Next, frozen sections were cut at a thickness of $30 \mu \mathrm{m}$ using a freezing microtome and collected in $0.1 \mathrm{~m}$ Tris-buffered saline, $\mathrm{pH} 7.4$, containing sodium azide.

For transmission electron microscopy, mice and rats ( $n=2$ each) were fixed $12 \mathrm{~d}$ postinjection with PFA and $1 \%$ GA in PB and postfixed in PFA in $\mathrm{PB}$ overnight. Seventy-micrometer-thick sections were cut on a vibratome (Microm HM $650 \mathrm{~V}$ ). Next, the hippocampal formation was excised, and postfixed in buffered $1 \%$ osmium tetroxide. After washing and dehydration in graded ethanol, and using block staining with $1 \%$ uranyl acetate in 50\% ethanol, samples were embedded in Glycidether100 (formerly Epon 812; Roth). Ultrathin sections were cut with a diamond knife on an Ultracut UCT (Leica Microsystems), collected on 300 mesh nickel grids and inspected using a Zeiss Libra 120 electron microscope operating at $120 \mathrm{kV}$. Digital images were captured with a Sharpeye $2 \mathrm{k}$ CCD camera (TRS, Troendle).

Light and electron microscopy. For immunoperoxidase staining, sections were applied to a streptavidin-biotin method and Ni-enhanced 3,3'-diaminobenzidine (DAB-Ni) as described previously (Härtig et al., 1995). The following primary antibodies were used: mouse antiparvalbumin (1:4000; Swant), guinea pig anti-parvalbumin (1:2000; Synaptic Systems), mouse anti-glutamic acid decarboxylase $67 \mathrm{kDa}$ isoform (GAD67; 1:5000, Millipore Bioscience Research Reagents) and guinea pig anti-VGAT, N terminus (1:500, Synaptic Systems) (Martens et al., 2008). For electron microscopy, immunoperoxidase staining of vibratome sections was performed with guinea pig anti-parvalbumin (1:2000) and DAB as chromogen.

For single or multiple immunofluorescence labeling, nonspecific immunoreactivity was suppressed by incubating specimens in a cocktail of $10 \%$ normal donkey serum (Jackson ImmunoResearch), 5\% BSA (Sigma) and 0.3\% Triton X-100 (Sigma) in PB. Sections were the exposed to select combinations of the following primary antibodies (in PB also containing $1 \%$ NDS and $0.2 \%$ Triton $\mathrm{X}-100$ for $48-72 \mathrm{~h}$ at $4^{\circ} \mathrm{C}$ ): guinea pig anti-parvalbumin (1:300, Synaptic Systems), rabbit anti-parvalbumin (1: 2000 , Swant), biotinylated rabbit anti-parvalbumin ( $20 \mu \mathrm{g} / \mathrm{ml}$; Synaptic Systems), rabbit anti-system A transporter 1 (SAT1, 1:1000) (Solbu et al., 2010), goat anti- $\mathrm{CB}_{1}$ cannabinoid receptor $\left(\mathrm{CB}_{1} \mathrm{R}, 1: 1000\right)$ (Kawamura et al., 2006), rabbit anti-VGLUT1 (1:2000, Synaptic Systems), guinea pig antiVGLUT1 (1:1000) (Kaneko et al., 2002), guinea pig anti-vesicular glutamate transporter 3 (VGLUT3, 1:1000) (Hioki et al., 2004), goat anti-calretinin (1:1000; Swant), mouse anti-calbindin D28k (CB, 1:1000; Swant), rabbit anti-GABA A $_{\text {receptor }} \alpha 1$ subunit $(5 \mu \mathrm{g} / \mathrm{ml}$ ) (Fritschy et al., 1992), mouse anti-GAD67 (1:5000; Millipore Bioscience Research Reagents), rabbit antineuropeptide Y (1:400, Diasorin), rabbit anti-somatostatin (1:400, Acris), guinea pig anti-GFAP (1:400, Synaptic Systems), rabbit anti-ionized $\mathrm{Ca}^{2+}$ binding protein adaptor molecule 1 (Iba-1; 1:200, Wako) and biotinylated mouse anti-neuronal nuclei (NeuN; $20 \mu \mathrm{g} / \mathrm{ml}$; Millipore Bioscience Research Reagents). After extensive rinsing in $\mathrm{PB}$, immunoreactivities were revealed by carbocyanine $(\mathrm{Cy}) 2,3$ or 5 -tagged secondary antibodies raised in donkey [1:200 (Jackson ImmunoResearch), $2 \mathrm{~h}$ at $\left.22-24^{\circ} \mathrm{C}\right]$. Sections were coverslipped in Entellan (in toluene; Merck). The omission of primary antibodies resulted in the absence of cellular staining in histological control experiments.

Laser-scanning microscopy and quantitative morphometry. Sections were inspected and images were acquired on a 780LSM confocal laserscanning microscope (Zeiss). Emission spectra for each dye were limited as follows: DAPI (420-485 nm), Cy2 (505-530 nm), Cy3 (560-610 nm), and Cy5 (640-720 nm). Image surveys were generated using the tile scan function with optical zoom ranging from $0.6 \times$ to $1.5 \times$ at $10 \times$ primary 

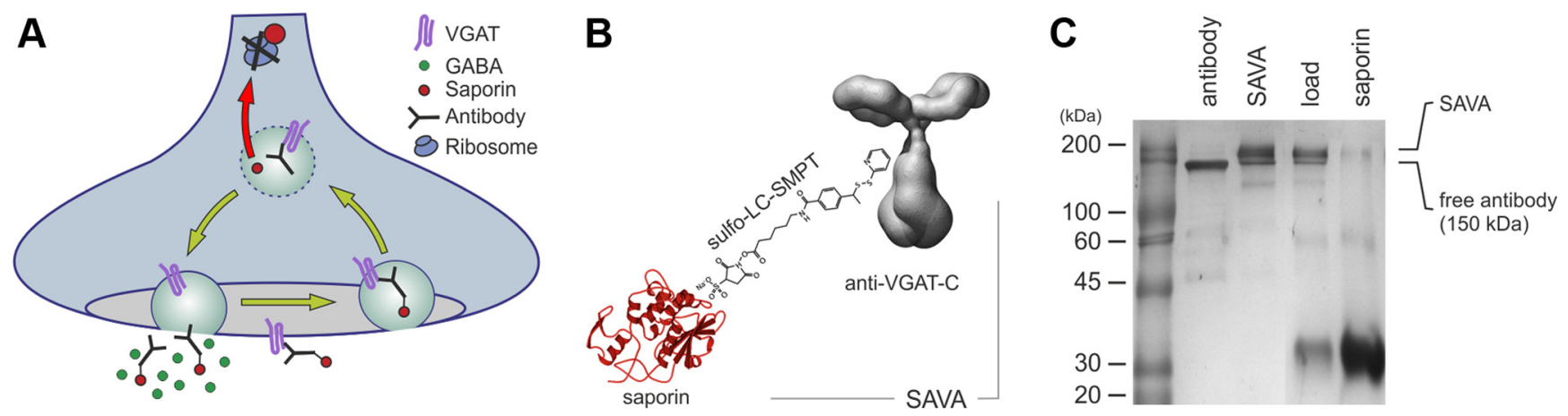

Figure 1. Molecular structure and biochemical analysis of SAVAs. A, Outline of the uptake mechanism allowing SAVAs to accumulate in inhibitory nerve terminals when VGAT's $C$ terminus is transiently externalized during synaptic vesicle recycling. $\boldsymbol{B}$, Schematic structure of SAVAs consisting of saporin coupled via a bifunctional cross-linker to an antibody directed against the luminal $C$ terminus of VGAT. C, Comparison of uncoupled anti-VGAT-C antibody, purified SAVAs, SAVA before final purification step (load), and free saporin by nonreducing SDS-PAGE.

magnification (objective: EC Plan-Neofluar $10 \times / 0.30$ ). Colocalization was defined as immunosignals being present without physical signal separation in $\leq 1.0 \mu \mathrm{m}$ optical slices at $40 \times$ (Plan-Neofluar $40 \times / 1.30$ ) or $63 \times$ (Plan-Apochromat $63 \times / 1.40$ ) primary magnification (Mulder et al., 2011). Multipanel figures were assembled in CorelDraw X5 (Corel Corp.). The brightness or contrast of confocal laser-scanning micrographs was occasionally linearly enhanced. Grayscale images of DABand DAB-Ni-stained neurons were captured using $5 \times, 20 \times$ and $40 \times$ objectives on a Zeiss Axiophot I microscope, equipped with a SpotInsight QE digital camera (Visitron).

The tissue size affected by SAVA lesions within the CA1 hippocampal subfield was determined in serial sections along the AP extent of the hippocampus. The cross-section interval was $150 \mu \mathrm{m}$. Quantitative analysis was performed off-line on images captured on a Zeiss 710LSM microscope at $10 \times$ primary magnification (image resolution: $2048 \times 2048$ pixels; 1 pixel $=1.65 \mu \mathrm{m})$. The lack of cellular parvalbumin immunoreactivity (see Fig. $4 A_{2}$ ) together with a demarcated trough in the fluorescence spectra (corresponding to the loss of perisomatic parvalbumin ${ }^{+}$terminals; see Fig. $4 A_{3}$ ) along the stratum pyramidale of the CA1-CA3 subfields were used to compute the lateral extent of SAVA lesions (ZEN2009 software package, Zeiss). First, we measured the distance along the pyramidal layer from the subiculum/CA1 border to the CA2/CA3 boundary. The latter boundary was identified by the appearance of the stratum lucidum. Within this trace, we have then determined the length of the parvalbumin-sparse region. The differential of these two measurements was used to compute the "percentage loss" of parvalbumin immunoreactivity in the dorsal Ammon's horn (see Fig. $4 C, C_{1}$ ).

We find that SAVA infusion indiscriminately reduced parvalbumin immunoreactivity in the somatodendritic axis of basket cells, as well as synaptic boutons. Therefore, we performed quantitative morphometry of these neuronal elements (Alpár et al., 2004a,b): the number of parvalbumin $^{+}$somata was cumulatively assessed in the CA1 oriens, pyramidal and radial layers. Image acquisition used threshold settings from the contralateral hippocampus in each section, and the density of objects in superimposed imaging frames (ImageJ) was expressed as percentage of the control value.

The number of perisomatic parvalbumin ${ }^{+}$boutons was determined in the pyramidal layer of the CA1 subfield in hippocampi infused with SAVA or unconjugated VGAT-C antibody. High-power images $(40 \times$ primary magnification) were acquired under identical laser-excitation, digitized, and uniform thresholds set for both the contra- and ipsilateral hippocampi $(n>20$ images/mouse, $n=3-4$ / group). Synapse profiles were manually identified since parvalbumin immunolabeling reveals dendrites, preterminal axons and synapses of GABAergic basket cells, potentially introducing bias if automated (indiscriminate) analysis methods are used. High-resolution graphic image files were exported into the UTHSCSA ImageTool (version 3.00; http://ddsdx.uthscsa.edu/dig/itdesc.html).

Histological analysis of granule cell dispersion. The MetaMorph software package (Molecular Devices) was used to quantify granule cell dis- persion in Yoyo 1 (nucleic acid)-stained sections ( $n=4 /$ mouse) across the dorsal hippocampus ( $n=3$ mice/group were analyzed). At least five consecutive measures were taken at $150 \mu \mathrm{m}$ intervals along the dorsal blade of the dentate gyrus (covering $>600 \mu \mathrm{m}$ surface area) per section. Each measure represents the distance between the hilar border of the granule cell layer and the outer border of the most distal granule cell somata (Antonucci et al., 2008). Data were collected blind to the experimental condition.

Statistics. Data were processed by SigmaStat (Systat Software Inc.). Student's $t$ test was used throughout except for the analysis of mIPSC and mEPSC frequencies (one-way ANOVA with Dunn's post hoc method). Nonparametric statistics (granule cell dispersion) was performed by Mann-Whitney's rank sum test. Data were expressed as means \pm SEM. A $P$ value of $<0.05$ was considered statistically significant.

\section{Results}

\section{Molecular target: the vesicular GABA transporter}

We hypothesized that SAVAs can selectively eliminate GABAergic neurons from neuronal circuitries upon binding of SAVA's antibody moiety to the luminal $\mathrm{C}$ terminus of VGAT (VGAT-C; Fig. $1 A$ ), which is transiently exposed on the outer neurolemmal surface upon synaptic vesicle fusion in the presynapse (Martens et al., 2008) during neurotransmitter release (Chaudhry et al., 1998). Since VGAT-C will be internalized upon activitydependent recycling of VGAT from the synaptic cleft (Fig. 1A), any drug or toxin bound to VGAT may be internalized. We have successfully applied anti-VGAT-C antibodies as structural backbone-when conjugated to stable fluorochromes - to label hippocampal GABAergic interneurons in vivo (Martens et al., 2008). SAVAs (Fig. $1 B$ ) were prepared by conjugating affinity-pure antibodies raised against VGAT-C via a cleavable and bifunctional cross-linker to saporin from Saponaria officinalis (Stirpe et al., 1983). Saporin inactivates eukaryotic ribosomes by catalyzing the hydrolytic depurination of adenosine residues (Sturm et al., 2009), while also showing remarkable resistance to denaturation and proteolysis intracellularly (Santanché et al., 1997). These properties, together with saporin's inability to enter cells in a nonspecific manner (Wiley, 1992) can be exploited to inactivate ribosomes (Wiley, 1992), unequivocally leading to the death of the presynaptic neuron (Wiley et al., 1995, 2009; Wrenn et al., 1996; Wiley and Lappi, 1997). Nondenaturing SDS-PAGE confirmed the purity of SAVAs (defined as the lack of residual free saporin), and confirmed a size shift equivalent to the molecular weight of saporin when comparing SAVAs to their cognate antibody (Fig. 1C). 

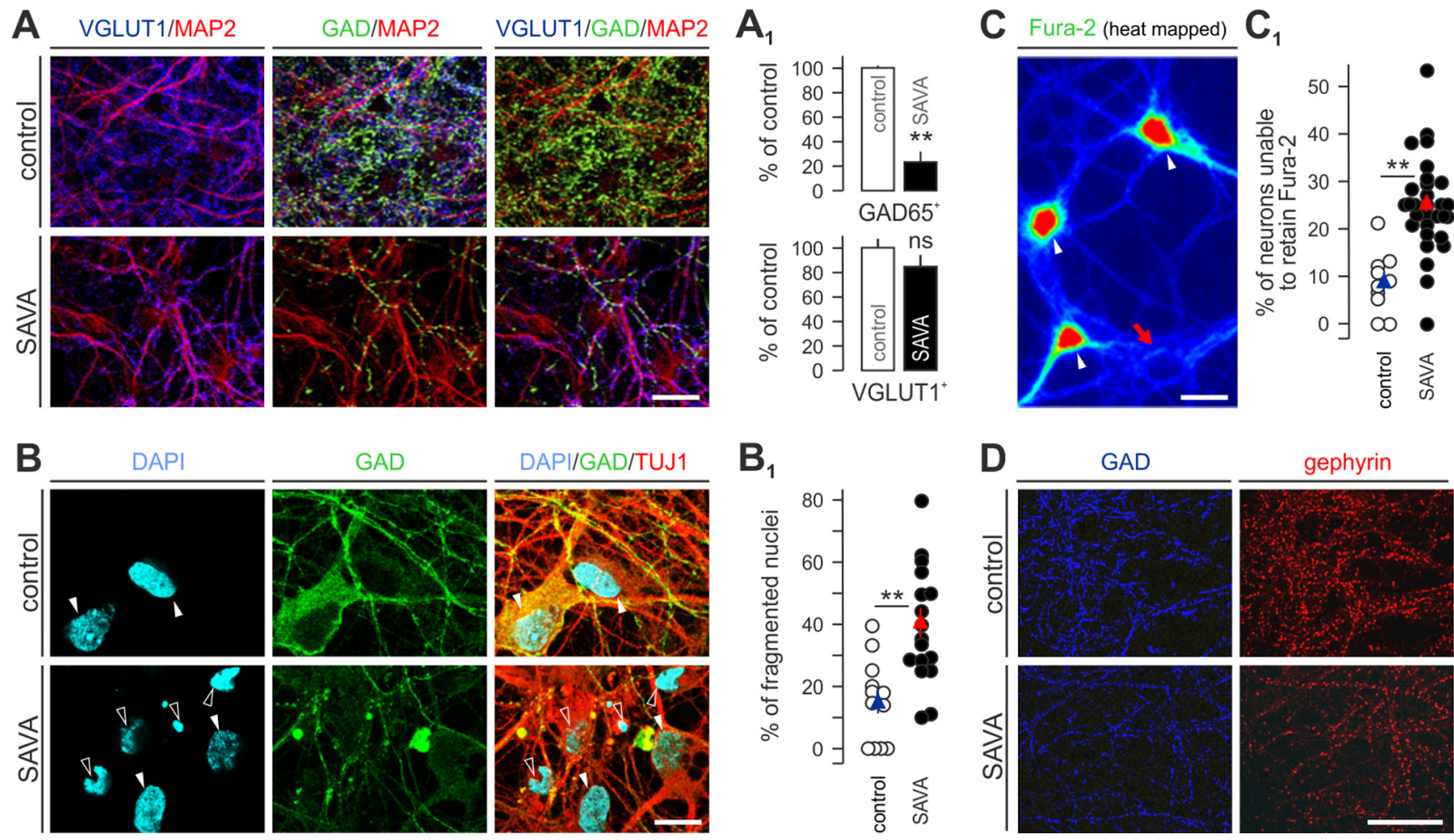

Figure 2. Morphological and functional analysis of primary hippocampal cultures exposed to SAVAs. A, Immunocytochemistry for GAD and VGLUT1 in primary cultures of hippocampal neurons (13 DIV) exposed to SAVAs for $3 \mathrm{~d}$. A specific loss of GAD ${ }^{+}$terminals occurred, while the distribution and density of VGLUT1 ${ }^{+}$terminals remained unchanged. $A_{1}$, Quantification of the density of $\mathrm{GAD65}^{+}$or VGLUT1 ${ }^{+}$synapses revealed $77 \%$ loss of inhibitory terminals (normalized to control; $p<0.05$ ) and $17 \%$ of excitatory synapses $(p=0.072$ ). Eighteen fields of view from control and treated preparations in triplicate experiments were analyzed. $\boldsymbol{B}, \boldsymbol{B}_{1}$, The proportion of neurons undergoing nuclear fragmentation significantly increased in SAVA-treated cultures. Open and closed

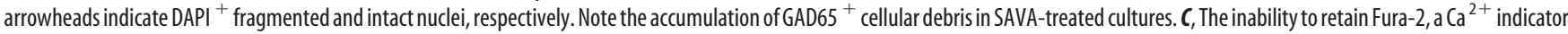
(arrow in red), has been used as an alternative means to verify that SAVA exposure increased membrane permeability associated to neuronal damage in vitro. Arrowheads point to intact, Fura-2-loaded neurons. Blue and red triangles represent the population mean for controls and SAVA, respectively. $\boldsymbol{D}$, The expression of gephyrin, a GABA receptor clustering protein at inhibitory postsynapses, is markedly reduced in SAVA-treated cultures. ${ }^{* *} p<0.01$ vs control. Data are expressed as means \pm SEM. Scale bars, $20 \mu \mathrm{m}$.

SAVAs selectively eliminate inhibitory presynapses in vitro We have exposed primary (mixed) cultures of hippocampal neurons to SAVAs $(0.16 \mathrm{ng} / \mathrm{ml})$ for $3 \mathrm{DIV}$, followed by determining the density of inhibitory and excitatory synapses by using GAD65 and VGLUT1 as respective phenotypic markers (Fig. 2 A). Quantitative analysis of synapse density after SAVA exposure revealed a strong reduction in $\mathrm{GAD} 65^{+}$boutons, likely presynaptic specializations harboring the ability to synthesize GABA (Asada et al., 1997; Chaudhry et al., 1998) (Fig. $2 A_{1}$ ). In contrast, the density of $\mathrm{VGLUT}^{+}$glutamatergic terminals remained largely unaffected (Fig. $2 A_{1}$ ). Next, we asked whether SAVAs irreversibly damage and eliminate GAD65 ${ }^{+}$neurons in vitro. We find, by analyzing the shape and size of $\mathrm{DAPI}^{+}$nuclei, a significant increase in nuclear fragmentation (that is, $<15 \mu \mathrm{m}$ in diameter with condensed chromatin; $p<0.01$; Fig. $2 B, B_{1}$ ). An increased percentage of neurons unable to retain Fura-2 perisomatically in $\mathrm{Ca}^{2+}$ imaging experiments upon SAVA exposure $(p<0.01$ vs control; Fig. $2 C, C_{1}$ ) emphasizes SAVA's ability to irreparably compromise neuronal integrity and functions in vitro.

The nonsignificant loss of glutamatergic terminals might reflect dynamic rearrangements to maintain the balance of excitation/inhibition upon the selective loss of inhibitory neurotransmission in vitro. Alternatively, this effect may be attributed to the colocalization of VGAT and VGLUTs in subpopulations of terminals, as described in cortical neurons (Fattorini et al., 2009). A concomitant reduction of gephyrin, the main $\mathrm{GABA}_{\mathrm{A}}$ receptor scaffolding protein (Sassoè-Pognetto et al.,
1995), was observed in SAVA-treated cultures (Fig. 2D), suggesting progressive disassembly of the postsynaptic apparatus in subsynaptic dendrites otherwise receiving inhibitory inputs.

To verify the specific reduction of inhibitory neurotransmission upon SAVA exposure, action potential-independent synaptic activity, in the form of mIPSCs and mEPSCs, was monitored in control and SAVA-treated cultures in the presence of TTX (1 $\mu \mathrm{M})$. SAVA exposure for 1 or 2 DIV significantly decreased the frequency of mIPSCs (control: $0.77 \pm 0.10 \mathrm{~Hz}(n=11)$ vs SAVA $_{1 \mathrm{DIV}}: 0.23 \pm 0.07 \mathrm{~Hz}(n=6)$, SAVA $_{2 \mathrm{DIV}}: 0.22 \pm 0.03 \mathrm{~Hz}$ $(n=17) ; p<0.001$; Figure $\left.3 A, A_{1}\right)$. In contrast, the mEPSC frequency did not change on $1 \mathrm{DIV}$ (control: $0.69 \pm 0.14 \mathrm{~Hz}(n=$

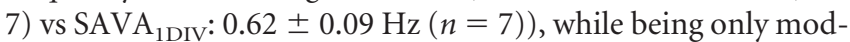
erately increased thereafter $\left(\mathrm{SAVA}_{2 \mathrm{DIV}}: 0.93 \pm 0.19 \mathrm{~Hz}(n=10)\right.$; Fig. $\left.3 B, B_{1}\right)$. This mEPSC response pattern suggests secondary compensatory changes upon removal of inhibitory neurotransmission in vitro. The amplitude of either mIPSCs $(20.62 \pm 1.95$ pA (control) vs $22.02 \pm 1.39 \mathrm{pA}\left(\mathrm{SAVA}_{2 \mathrm{DIV}}\right), p>0.4$; Fig. $\left.3 A_{2}\right)$ or mEPSCs $(-26.72 \pm 6.15 \mathrm{pA}$ (control) vs $-20.43 \pm 3.55 \mathrm{pA}$ (SAVA), $p>0.3$; Fig. $3 B_{2}$ ) remained unchanged.

Neuronal networks develop in vitro as self-organized systems, displaying highly synchronized activity (Bacci et al., 1999; Eytan and Marom, 2006). This synchronous activity relies on glutamatergic neurotransmission (Bacci et al., 1999), and is controlled by the local GABAergic neuronal network (Bacci et al., 2002; Butuzova and Kitchigina, 2008; Pozzi et al., 2008). Consistent with a reduction of inhibitory inputs, SAVA-treated cultures and loaded 
with Fura-2, a $\mathrm{Ca}^{2+}$ indicator dye (Fig. $\left.2 C, C_{1}\right)$, displayed a progressive increase in the frequency of $\mathrm{Ca}^{2+}$ oscillations measured as the reduction of the interburst interval in vitro (Fig. $3 C-C_{2}$ ).

\section{SAVAs disrupt inhibitory}

neurotransmission in the hippocampus We have stereotaxically injected SAVA into the CA1 region of the dorsal hippocampus $(0.5 \mathrm{mg} / \mathrm{ml}$ at a final volume of 2 and $5 \mu$ into mice and rats, respectively) to assess its lesion efficacy and specificity in vivo. The focal loss of parvalbumin ${ }^{+}$ basket cells (Fig. $4 A-A_{2}$ ) and their perisomatic terminals (Fig. $4 A_{3}-B_{1}$ ) in the pyramidal layer along the dorsal Ammon's horn (CA1 to CA3 subfields) was demonstrated in SAVA-lesioned mice relative to recipients of unconjugated VGAT-C antibody (unc-Ab) and nonlesioned controls. As Figure $4, C-C_{3}$, shows, SAVA microinjections produced extensive loss of parvalbumin immunoreactivity that affected $\pm 600 \mu \mathrm{m}$ in either direction from the lesion site, and gradually tailed-off distally [spared surface area: $19.42 \pm$ $6.78 \%$ (the length $(\mu \mathrm{m})$ of the CA1 subfield containing parvalbumin ${ }^{+}$perisynaptic boutons in stratum pyramidale]; bouton density in stratum oriens: $16.48 \pm$ $4.50 \%$; bouton density in stratum pyramidale: $16.15 \pm 4.85 \%$; density of perikarya: $0 \%$ (all vs control and expressed as percentage of control; $p<0.01)$. unc-Ab affected neither the density of parvalbumin ${ }^{+}$synaptic terminals (Fig. $4 C_{2}$ ) nor the laminar distribution of parvalbumin ${ }^{+}$perikarya (Fig. $4 C_{3}$; bouton density in stratum oriens: $90.11 \pm 8.57 \%$; bouton density in stratum pyramidale: $95.31 \pm 8.06 \%$; density of perikarya: $105 \pm 0.98 \%$ (all vs control and expressed as percentage of control; $p>0.5$ ).

Since SAVA infusion might affect parvalbumin's expressional control ("marker drop-out") rather than the physical elimination of parvalbumin ${ }^{+}$neurons from the CA1 subfield, we mapped the distribution of GAD67 (Asada et al., 1997) and SAT1, an alternative neurochemical marker of parvalbumin ${ }^{+}$basket cells (Solbu et al., 2010). The loss of GAD67 and SAT1 was found comparable to that of parvalbumin upon SAVA but not unc-Ab infusion (Fig. $\left.4 D, D_{1}, E-E_{2}\right)$. We have simultaneously established the SAVA/ unc-Ab-induced rearrangement of $\mathrm{CB}_{1} \mathrm{Rs}$ in the hippocampus. $\mathrm{CB}_{1} \mathrm{Rs}$ label cholecystokinin-containing GABAergic interneurons (high expression) whose axon terminals concentrate in the pyramidal layer (Katona et al., 1999; Tsou et al., 1999) (Fig. $4 E, F)$, as well as VGLUT1 ${ }^{+}$glutamatergic afferents (intermediate/low expression), particularly in the inner molecular layer of the dentate gyrus (Monory et al., 2006). We demonstrate that SAVA infusion eliminated the GABAergic component of $\mathrm{CB}_{1} \mathrm{R}$ immunoreactivity in the hippocampus (Fig. $4 E_{2}, F_{2}$ ), the localization of remnant $\mathrm{CB}_{1} \mathrm{R}$ being reminiscent to those in

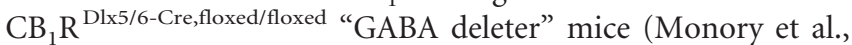
2006). unc-Ab disrupted neither $\mathrm{CB}_{1} \mathrm{R}$ nor VGLUT1 localization in the hippocampus (Fig. $4 E_{1}, F_{1}$ ). The unchanged VGLUT1 immunoreactivity in hippocampal territories deprived of GABAergic innervation (Fig. $4 E_{2}, F_{2}$ ) reinforces our hypothesis that
SAVAs can selectively impair the GABAergic component of the hippocampal circuitry.

SAVAs' experimental potential was further validated by their injection into the rat hippocampus (Fig. 4G). We find the complete elimination of parvalbumin ${ }^{+}$(Fig. $4 H, H_{1}$ ) and GAD67 ${ }^{+}$ perikarya (Fig. $4 I, I_{1}$ ) in the pyramidal as well as infra- and suprapyramidal layers of the injected hemisphere after a $12 \mathrm{~d}$ survival period. The scarcity of $\mathrm{GAD}^{+} 7^{+}$axons emphasizes the reduction of inhibitory axosomatic synapses locally innervating pyramidal cell assemblies (Buzsáki et al., 2007).

\section{SAVA lesions impact multiple interneuron subclasses}

We predicted that local-circuit GABAergic interneurons must be indiscriminately impacted upon SAVA infusion since VGAT is ubiquitously present in GABAergic terminals. We tested this hypothesis by using antibodies against $\mathrm{Ca}^{2+}$-binding proteins (Fig. $5 A-E_{1}$ ), VGLUT3 (Fig. $5 A-B_{1}$ ) and neuropeptides (Fig. 5D- $E_{1}$ ), as well as the postsynaptic $\mathrm{GABA}_{\mathrm{A}}$ receptor $\alpha 1$ subunit (Fritschy et al., 1992; Riedel et al., 1998) (and their combinations) to reveal whether SAVA impacts both the synapse and somatodendritic integrity of hippocampal interneurons. Confocal laser-scanning microscopy showed the indiscriminate removal of calretinin ${ }^{+}$, $\mathrm{CB}^{+}$, VGLUT3 $^{+}$, neuropeptide $\mathrm{Y}^{+}$and somatostatin ${ }^{+}$interneurons from the CA1 subfield by focal SAVA injections.

However, SAVA affected neither VGLUT3 immunoreactivity at the border of strata radiatum and lacunosum moleculare, representing serotonergic (vesicular monoamine transporter type $2^{+}$) afferents (Somogyi et al., 2004) nor $\mathrm{CB}^{+} \mathrm{CA} 1$ pyramidal cells (Fig. $5 A, A_{1}$ ). In addition, prominent $\mathrm{GABA}_{\mathrm{A}}$ receptor $\alpha 1$ subunit immunoreactivity (Fig. 5C, $C_{1}$ ), identifying postsynaptic special- 

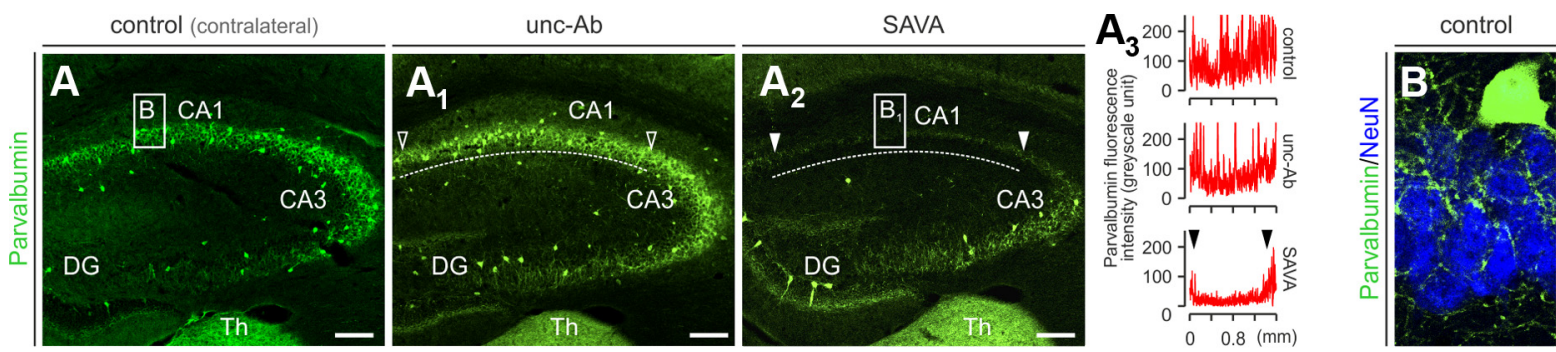

SAVA

C

$\mathrm{C}_{1}$

$\mathrm{C}_{2}$

$\mathrm{C}_{3}$
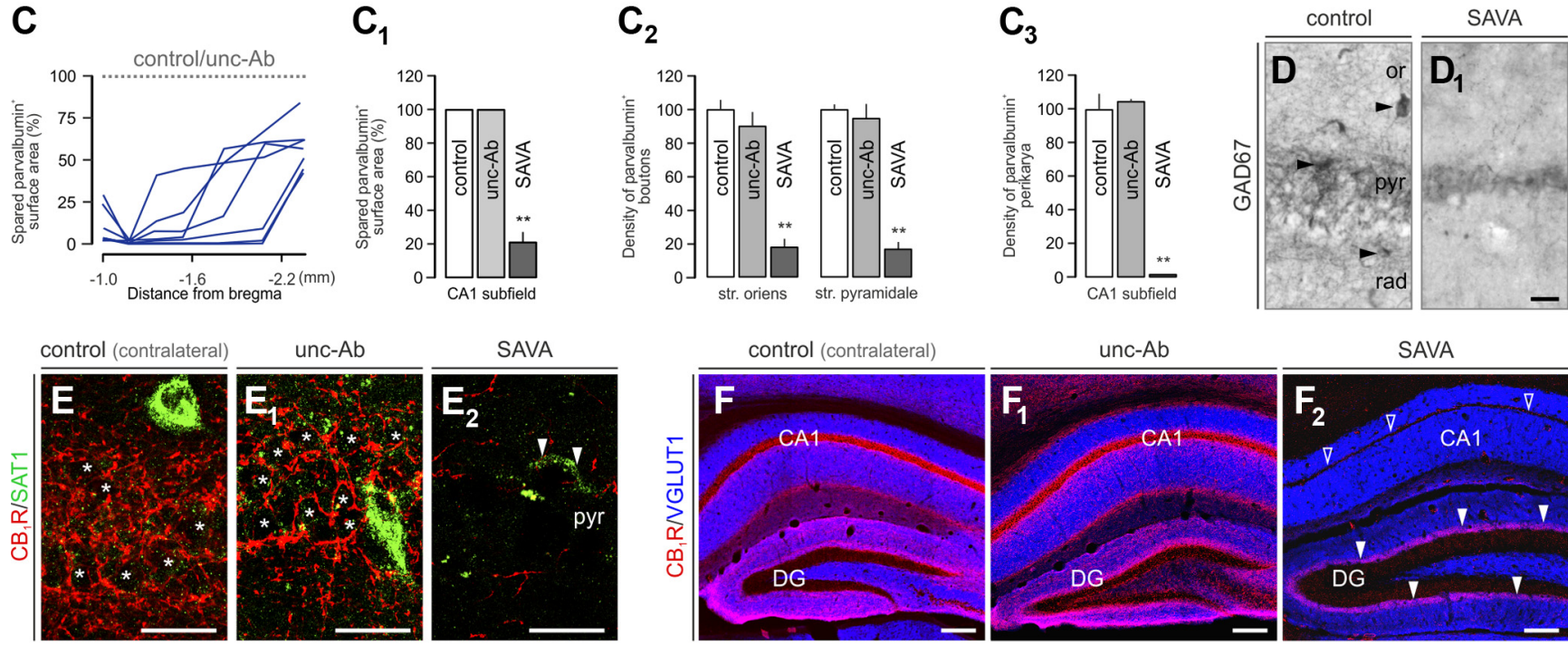

unc-Ab

SAVA
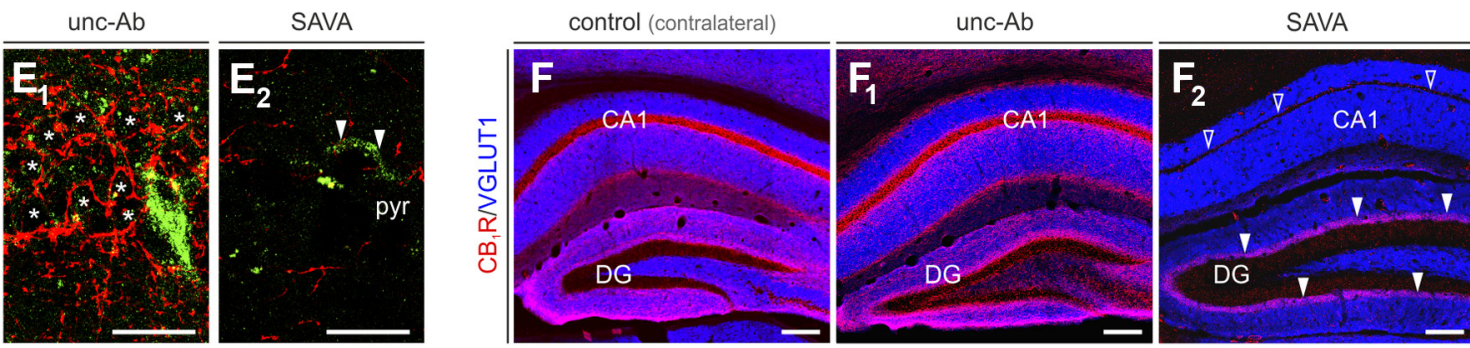

rat - dorsal hippocampus (coronal)

rat - control

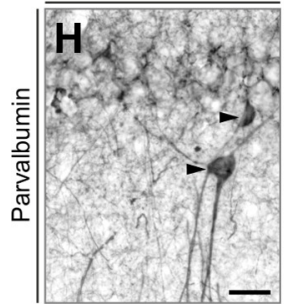

rat - SAVA



rat - control

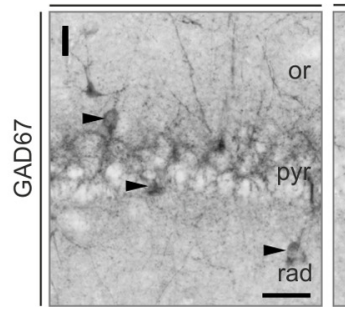

rat - SAVA



Figure 4. SAVA immunolesions compromise GABAergic but not glutamatergic neuronal identity markers in the rodent hippocampus. $A-A_{2}$, Comparison of parvalbumin ${ }^{+}$local-circuit interneurons in control $(A)$, unc-Ab-treated $\left(A_{1}\right)$, or SAVA-lesioned $\left(A_{2}\right)$ hippocampi of mice 12 d postlesion. $A_{3}$, Distribution of parvalbumin immunofluorescence along the pyramidal layer in the $C A 1-C A 3$ subfields of the treatment groups. Arrowheads denote the lateral extremities, while dashed line identifies the extent of the surface area showing reduced parvalbumin immunoreactivity in the CA1-3 subfields. Note the sharp SAVA lesion border (arrowheads), as revealed by the lack of parvalbumin ${ }^{+}$terminals, in $\boldsymbol{A}_{3}, \boldsymbol{B}, \boldsymbol{B}_{1}$, The loss of parvalbumin ${ }^{+}$interneurons and their terminals was found associated with reduced density of NeuN ${ }^{+} \mathrm{CA}$ pyramidal cells. $\mathbf{C}-\boldsymbol{C}_{3}$, Quantitative analysis of lesion extent along the anterior-posterior axis of the hippocampus $\left(\boldsymbol{C}, \boldsymbol{C}_{i}\right.$; ${ }^{\prime \prime}$ ppared surface area" refers to the percentage of $C A 1$ region harboring parvalbumin immunoreactivity), the density of parvalbumin ${ }^{+}$boutons $\left(\boldsymbol{C}_{2}\right)$ and somata $\left(\boldsymbol{C}_{3}\right) .{ }^{* *} p<0.01$ vs contralateral/unc-Ab groups. $\boldsymbol{D}-\boldsymbol{F}_{2^{\prime}}$ We confirmed the SAVA-induced loss of GABAergic interneurons by using GAD67 $\left(\boldsymbol{D}, \boldsymbol{D}_{1}\right), \operatorname{SAT1}\left(\boldsymbol{E}-\boldsymbol{E}_{2}\right)$ and $\mathrm{CB}_{1} \mathrm{Rs}\left(\boldsymbol{E}-\boldsymbol{F}_{2}\right)$ as alternative markers of perisomatic basket cells. Arrowheads in $\boldsymbol{D}$ and $\boldsymbol{E}_{2}$ point to perisomatic profiles, asterisks denote the location of pyramidal cells. The finding that SAVA selectively eliminates $\mathrm{CB}_{1} \mathrm{R}$ immunoreactivity in the CA1 subfield (open arrowheads) but not dentate gyrus (solid arrowheads), and leaves VGLUT1 distribution unchanged reinforces SAVA's specificity toward inhibitory targets. G, Lateral extent of SAVA neurotoxicity in the rat hippocampus. $\boldsymbol{H}-\boldsymbol{I}_{\boldsymbol{1}}$, SAVA infusion in the rat hippocampus replicated prior findings from mouse, i.e., reduced parvalbumin $\left(\boldsymbol{H}_{\boldsymbol{1}}\right)$ and GAD67 immunoreactivities $\left(\boldsymbol{I}_{\boldsymbol{1}}\right)$ relative to controls $(\boldsymbol{H}, \boldsymbol{I})$. CA1-CA3, Cornu ammonis subfields; DG, dentate gyrus; Th, thalamus; or, stratum oriens; pyr, stratum pyramidale; rad, stratum radiatum. Scale bars: $A-A_{2}, F-F_{2}, 500 \mu m ; B_{1}, D_{1}, H-I_{1}, 25 \mu \mathrm{m} ; \boldsymbol{E}-\boldsymbol{E}_{2}, 15 \mu \mathrm{m}$.

izations apposing inhibitory afferents (Fritschy et al., 1992) was seen in the SAVA-lesioned hippocampus. Cumulatively, these data together with preserved VGLUT1 and $\mathrm{CB}_{1} \mathrm{R}$ distributions (Fig. $4 F-F_{2}$ ), suggest that SAVA selectively perturbs GABAergic neurotransmission.

\section{Demise of GABAergic interneurons activates microglia}

SAVA-induced cellular injury to GABAergic interneurons triggered the focal activation of Iba- ${ }^{+}$microglia (Fig. $6 A_{2}$ ) — and to a lesser extent of glial fibrillary acidic protein ${ }^{+}$astrocytes-relative to unc-Ab-treated or naive controls (Fig. 6A, $A_{1}$ ).

At the ultrastructural level, regularly shaped parvalbumin ${ }^{+}$ perikarya were found in naive or unc-Ab-treated tissues (Fig.
$6 B)$. In contrast, SAVA immunolesion led to severe interneuron fragmentation, as revealed by immunolabeling for parvalbumin combined with transmission electron microscopy, $12 \mathrm{~d}$ postinjection (Fig. $6 B_{1}$ ). This was associated with lesionactivated microglia phagocytosing parvalbumin ${ }^{+}$neuronal debris (Fig. $6 B_{2}$ ).

\section{SAVA-induced disruption of GABAergic neurotransmission impacts neuronal excitability}

SAVA-induced removal of GABAergic inhibitory components from the hippocampal circuitry can alter the excitation/inhibition balance and evoke pathological discharges if the magnitude of network disruption reaches a critical threshold. To address 

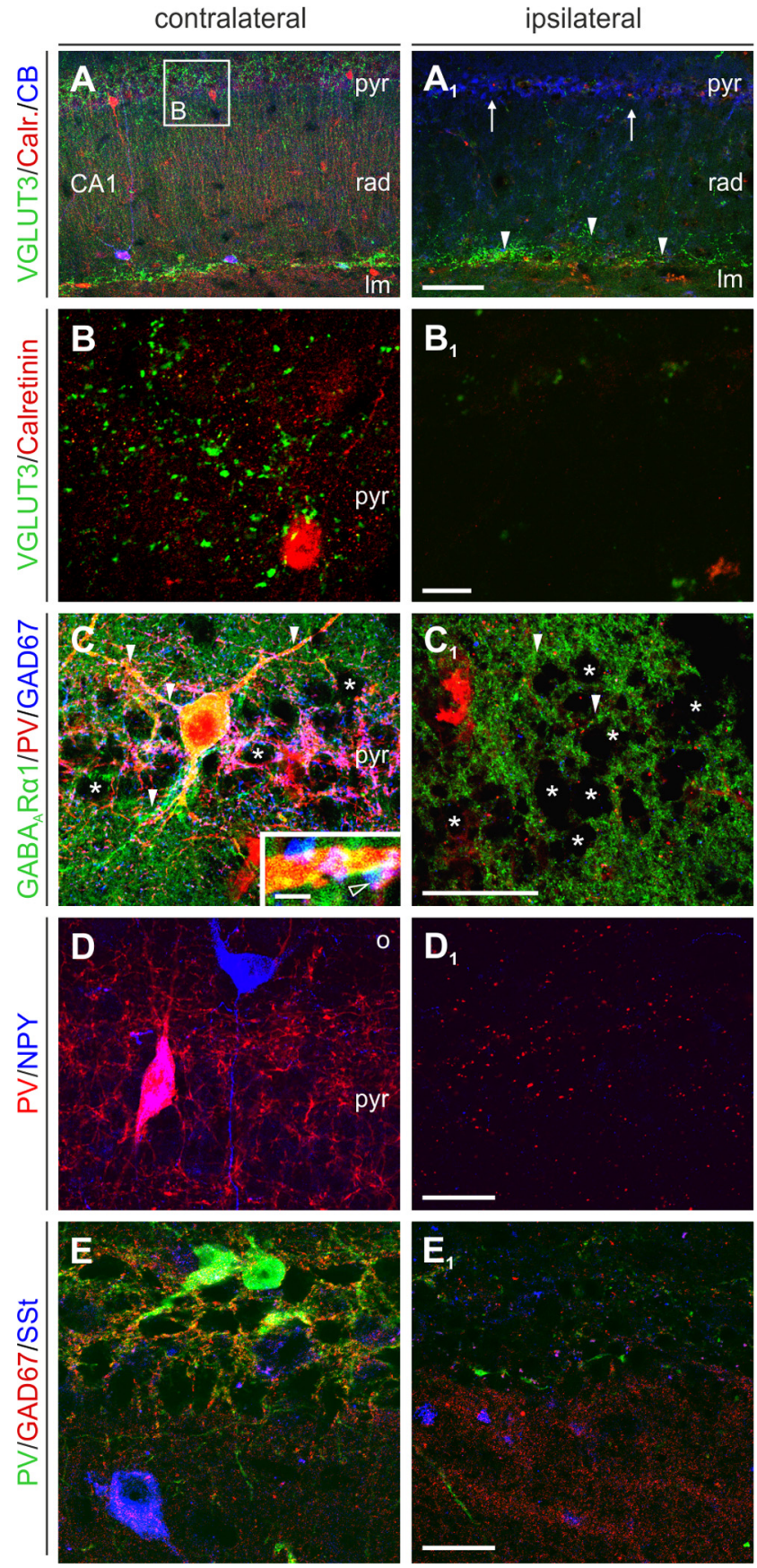

Figure 5. SAVA indiscriminately eliminates GABAergic interneurons in mouse hippocampus. $\boldsymbol{A}$, $A_{1}$, Overview of the CA1 subfield depicting the loss of $\mathrm{CB}^{+}$, calretinin ${ }^{+}$or VGLUT3 ${ }^{+}$interneurons but not VGLUT3 ${ }^{+}$serotonergic afferents (arrowheads, $A_{7}$ ) at the stratum radiatum/lacunosum moleculare border (Somogyi et al., 2004) or C ${ }^{+}$pyramidal cells (arrows). $\boldsymbol{B}, \boldsymbol{B}_{1}$, High-resolution photomicrographs showing the loss of perisomatic VGLUT3 ${ }^{+}$afferent inputs to $C A 1$ pyramids ipsilateral to SAVA infusion. C, Simultaneous detection of parvalbumin, GAD67 and the $\alpha 1$ subunit of GABA ${ }_{A}$ receptors (arrowheads) establishes clear segregation of GAD67 and $\alpha 1$ to presynaptic and postsynaptic loci (arrowhead in inset points to $\mathrm{GAD} 67^{+}$presynapse). $C_{1}$, SAVA infusion eliminates parvalbumin and GAD67 but not $\alpha 1$ immunoreactivity. Asterisks denote the location of pyramidal cells. $\boldsymbol{D}-\boldsymbol{E}_{\boldsymbol{1}}$, Similarly, SAVA eliminates neuropeptide Y (NPY) and somatostatin (SSt) immunoreactivities. Pink color in Didentifies a dual-labeled interneuron. Im, Stratum lacunosum moleculare; 0 , stratum oriens; pyr, stratum pyramidale; rad, stratum radiatum. Scale bars: $A_{1}, 200 \mu \mathrm{m} ; \boldsymbol{B}_{1}-\boldsymbol{E}_{1}, 25 \mu \mathrm{m}$.

this, we performed EEG recordings in freely moving mice 11 or $12 \mathrm{~d}$ after intrahippocampal delivery of SAVA, unc-Ab or controls. In SAVA-injected mice, we find a significant increase in the occurrence of high-amplitude electroencephalographic dis-
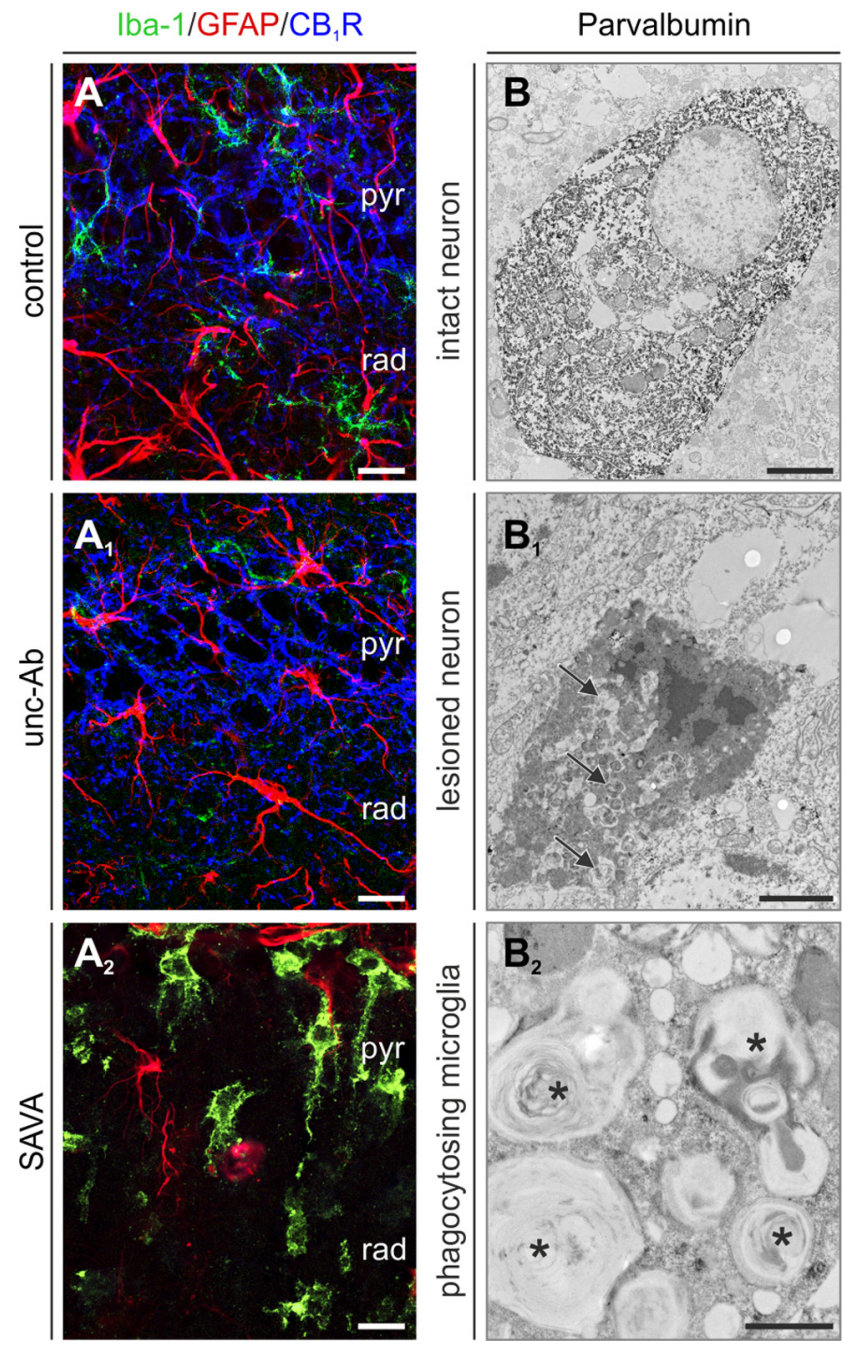

Figure 6. SAVA-induced neurodegeneration increases glial phagocytosis. $A-A_{2}$, Concomitant detection of astroglia, microglia/macrophages and $\mathrm{CB}_{1} \mathrm{R}^{+}$perisomatic (GABAergic) synapses in the hippocampus of mice $12 \mathrm{~d}$ after immunolesion. While surveying/nonactivated Iba- $1^{+}$microglia have been found residing in the contralateral hemisphere $(\boldsymbol{A})$ and upon unc-Ab infusion $\left(\boldsymbol{A}_{\boldsymbol{1}}\right)$ SAVA infusion increased microglia infiltration of the lesioned hippocampal territory. GFAP immunoreactivity, an astroglia marker, has been moderately affected. The loss of $\mathrm{CB}_{1} \mathrm{R}^{+}$synapses was used to confirm SAVA lesion efficacy. $\boldsymbol{B}-\boldsymbol{B}_{2}$, Ultrastructural analysis of parvalbumin ${ }^{+}$perikarya in naive tissue $(\boldsymbol{B})$ vs parvalbumin immunoreactivity $12 \mathrm{~d}$ after immunolesion $\left(\boldsymbol{B}_{1}, \boldsymbol{B}_{2}\right)$. Note the apparent degeneration of parvalbumin ${ }^{+}$neurons (arrows; $\boldsymbol{B}_{7}$ ), and phagocytosing microglia with several phagosomes (asterisks; $\boldsymbol{B}_{2}$ ). Scale bars: $\boldsymbol{A}-\boldsymbol{A}_{2}, 15 \mu \mathrm{m} ; \boldsymbol{B}$, $B_{1}, 2 \mu \mathrm{m} ; \boldsymbol{B}_{2}, 1 \mu \mathrm{m}$.

charges (the voltage threshold was set to 4.5 times the SD of the EEG signal, Fig. $7 A, B$ ) as shown by 1-h-long representative recordings (Fig. 7A-A $A_{2}$ ) performed over two consecutive days (Antonucci et al., 2008). Next, we tested whether these spiking events are restricted to the hippocampus by analyzing EEG recordings from the cerebral cortex. These experiments showed that the foci of altered EEGs were in the hippocampus, and excluded neocortical structures (Fig. 7C). Generalized seizures were only sporadically observed during routine handling of lesioned mice. Thus, these data suggest that SAVAs can profoundly alter hippocampal activity by impacting the synchronization and temporal control of excitatory principal cells.

\section{SAVA-induced cellular reorganization in the hippocampus}

Sustained failure of GABAergic neurotransmission in, e.g., temporal lobe epilepsy, induces the progressive loss of pyramidal 
A

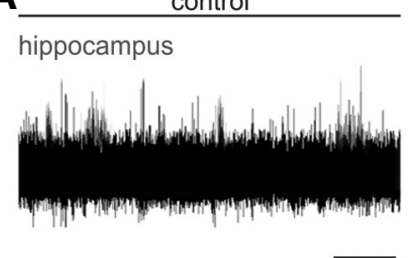

$\mathbf{A}_{1}$

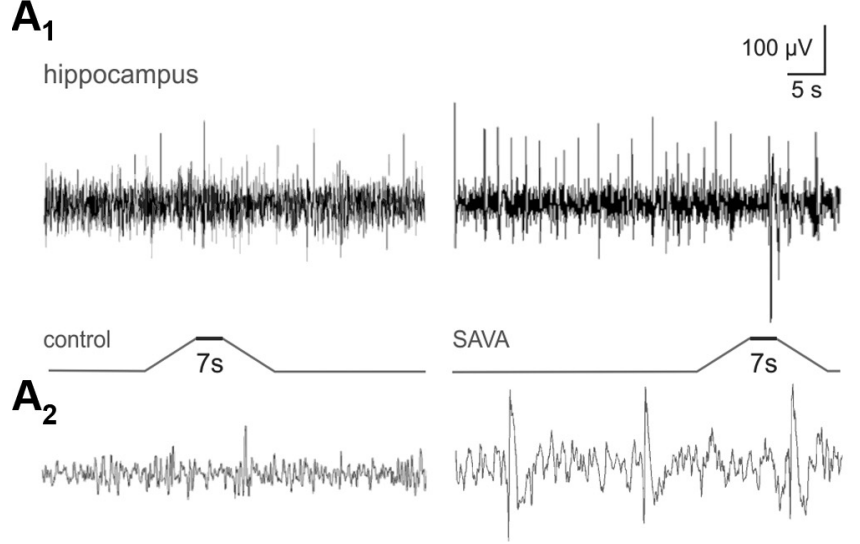

B

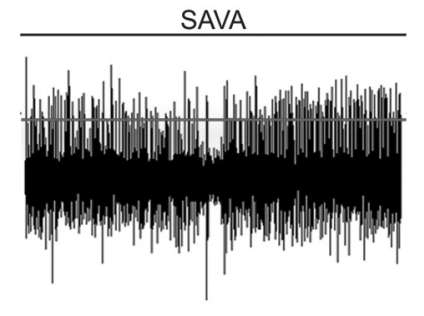

C
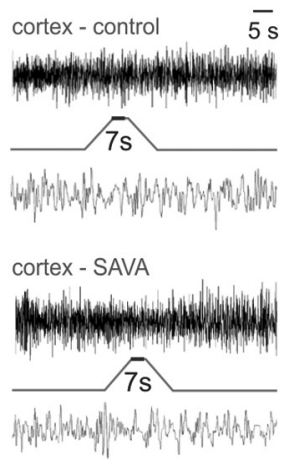

Figure 7. Altered EEG upon intrahippocampal SAVA infusion. Adult mice received bilateral SAVA, unc-Ab or control injections in the hippocampi, followed by electrophysiological and morphological verification of the lesion size by means of parvalbumin immunolabeling $12 \mathrm{~d}$ after delivery of the immunotoxin. $A-A_{2}$, EEG recordings of spontaneous hippocampal activity reveal the appearance of high-amplitude and high-frequency events as shown at both low $(\boldsymbol{A})$ and high temporal resolution $\left(\boldsymbol{A}_{\boldsymbol{1}}\right)$ with individual discharges depicted in $\left(\boldsymbol{A}_{2}\right)$. Horizontal bar indicates the threshold above which single events were considered as pathological alterations in the EEG trace. $\boldsymbol{B}$, Quantification of the frequency of spontaneous spikes. ${ }^{*} p<0.05$; ns, nonsignificant relative to sham controls. $\boldsymbol{C}$, Altered EEG records were not observed in the cerebral cortex. Data were expressed as means \pm SEM.

cells in CA subfields, as well as dispersion of dentate granule cells (Boulland et al., 2007; Antonucci et al., 2008). Although VGLUT1 ${ }^{+}$hippocampal afferents remained preserved (Fig. $4 \mathrm{~F}-$ $F_{2}$ ), we find the loss of CA1 pyramidal cells $12 \mathrm{~d}$ after SAVA lesions (Fig. $4 B, B_{1}$ ). Since the widespread loss of interneurons is predicted to precede that of CA1 pyramidal cells in the SAVAinfused hippocampus (Fig. 5A, $A_{1}$ ), we assume that SAVA evokes a neurodegenerative cascade-accompanied by the adaptive reorganization of neuronal networks-reminiscent to that seen in recurrent epilepsy. Therefore, we used a survival period of 10 weeks to assess gross modifications to hippocampal circuitries. By using double-labeling for parvalbumin and VGLUT1 we show reduced parvalbumin immunoreactivity in CA1-3 subfield as well as dentate gyrus of SAVA-exposed mice (Fig. 8A, $A_{1}, C, C_{1}$ ). In parallel, we find marked shrinkage- but not redistribution or loss of laminar identity - of VGLUT1 ${ }^{+}$synapses in the strata oriens and radiatum of SAVA-lesioned hippocampi (Fig. 8 $A^{\prime}-$ $B_{1}$ ). We attribute the thinning of VGLUT1-packed laminae to the reduced dendritic arbor of remnant CA1 pyramidal cells.

Concomitantly, the dentate gyrus expands to replace lost neuronal structures in CA1-3 subfields (Fig. $8 A_{1}{ }^{\prime}$ ). This is achieved by the dispersion of dentate granule cells. Quantitative analysis $12 \mathrm{~d}$ postlesion demonstrates $\sim 2$-fold increase in the width of the dentate granule cell layer in SAVA-treated hippocampi (126 $\mu \mathrm{m}$ (median); 25-75\% interquartile ranges: $109.2-139.1 \mu \mathrm{m})$ relative to controls (70.9 $\mu \mathrm{m}$ (median); 25-75\% interquartile ranges: 64-77.8 $\mu \mathrm{m}$; Mann-Whitney rank sum test, $p<0.001)$. Although granule cells roughly retain their distribution in the inner and outer blades of the dentate gyrus, their expression of SAT1 (Fig. $8 D, D_{1}$ ), a glutamine transporter expressed by developing neurons prenatally (Weiss et al., 2003), suggests the adaptive ex- pansion of the dentate gyrus 10 weeks after immunotoxin lesions. In sum, these alterations resemble changes of neuronal architecture observed in rodent models of mesial temporal lobe epilepsy and human patients (Pitkänen and Sutula, 2002).

\section{Discussion}

SAVAs extend the panel of immunotoxins (Wiley, 1992) specific toward chemically defined neuronal subpopulations. Saporinconjugated antibodies are versatile tools to remove neurons from select brain microcircuits: e.g., (1) application of 192IgG-saporin-binding to the lowaffinity neurotrophin receptor $\mathrm{p} 75^{\mathrm{NTR}}$-allows selective immunolesions to cholinergic projection neurons in the basal forebrain (Heckers et al., 1994; Wiley et al., 1995), (2) noradrenergic neurons can specifically be eliminated by immunotoxins made of antibodies against dopamine $\beta$-hydroxylase and saporin (Wrenn et al., 1996), (3) substance P-saporin (Wiley and Lappi, 1997) destroys neurokinin-1 receptor-expressing neurons in the rodent brain, while (4) neuropeptide Y-saporin (Wiley et al., 2009) selectively targets neuropeptides $Y$ receptor-containing neurons in the spinal cord. The overall significance of these lesion strategies is that they provide specific information on and mechanistic insights into the hierarchical organization, physiological roles and pathophysiological significance of the particular neurotransmitter system under study.

The selective manipulation of inhibitory components in neuronal networks has hitherto been achieved through genetic silencing (Murray et al., 2011) or optogenetics (Boyden et al., 2005), conferring cell type specificity. However, previous attempts to destruct inhibitory neurons by means of ribosome inactivation failed since the GABA transporter 1, GAT-1, a preferred molecular target (Radley et al., 2009; Pang et al., 2011), is expressed by both neurons and astroglia (Schousboe, 2000; Madsen et al., 2010), precluding selective immunolesions. Here, we have characterized a novel anti-VGAT antibody conjugated to saporin as "destruction complex". We have chosen VGAT since recent modeling and experimental data corroborate that, contrasting initial predictions of its transmembrane topology (McIntire et al., 1997), VGAT's C terminus is in fact exposed on the extracellular membrane surface of presynapses during synaptic vesicle fusion (Martens et al., 2008). Therefore, VGAT can be exploited to selectively and efficiently target inhibitory GABAergic (inter)neurons.

The size of SAVA lesions is reproducible when using short postlesion intervals (up to $12 \mathrm{~d}$; Fig. $4 C, C_{1}$ ). Yet the magnitude of adaptive structural rearrangements within the hippocampal circuitry upon SAVA infusion was found more variable, including scar formation, mild partial and complete lesions after a survival period of 10 weeks (Fig. $8 C, C_{1}$ ). We note that, similar to an earlier report on intraparenchymal immunotoxin application (BergerSweeney et al., 1994), SAVA infusion in the hippocampus can compromise the integrity of nervous tissue proximal to the injec- 

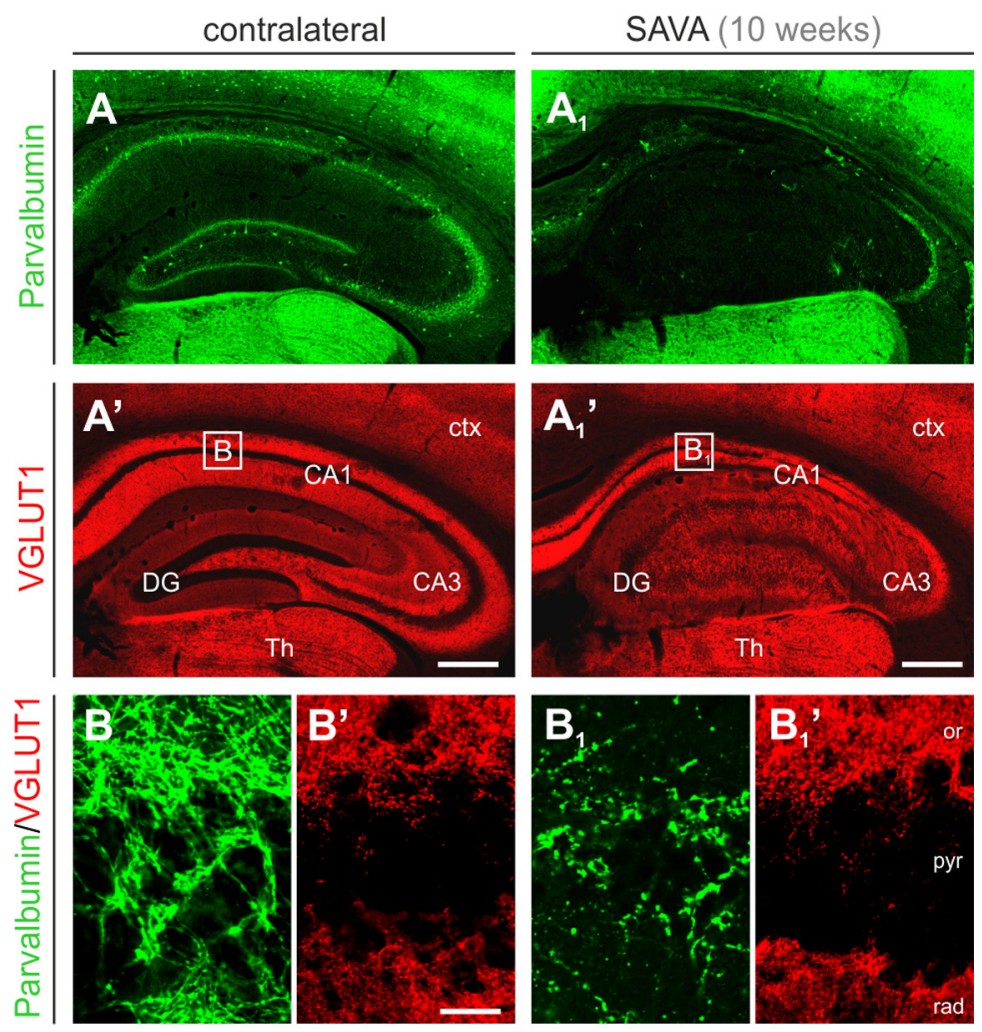

C

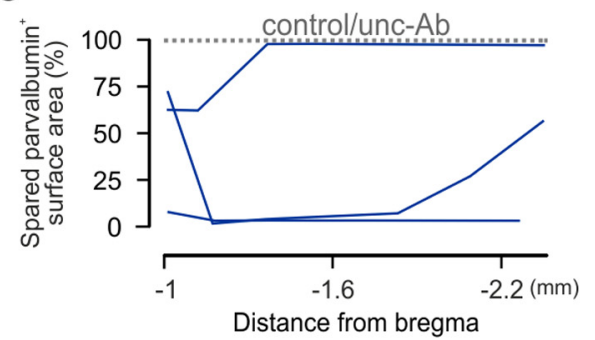

$\mathrm{C}_{1}$
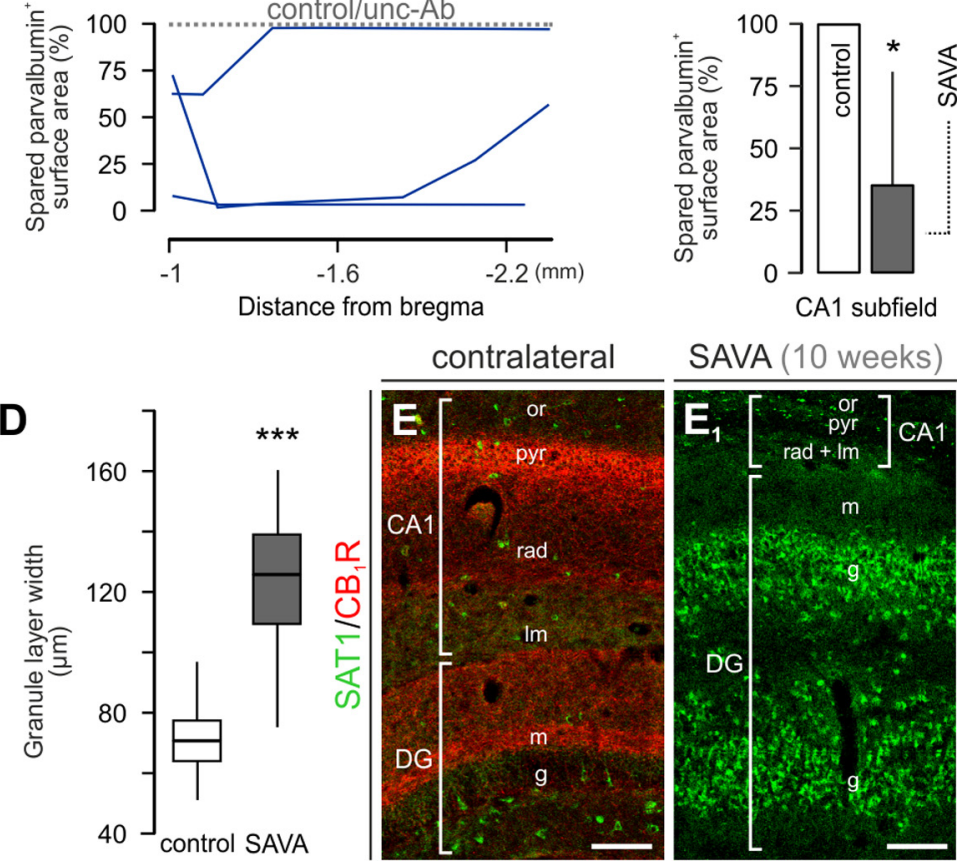

Figure 8. Adaptive structural rearrangements of the SAVA-lesioned hippocampus. $\boldsymbol{A}_{1}, \boldsymbol{A}_{\boldsymbol{1}}$, Progressively augmented loss of parvalbumin ${ }^{+}$neurons and their terminals, also impacting the dentate gyrus $\left(\boldsymbol{A}_{1}\right)$ was seen 10 weeks after SAVA infusion. In contrast, excitatory VGLUT1 ${ }^{+}$afferents were preserved $\left(\boldsymbol{B}, \boldsymbol{B}_{1}\right)$. Note the significant shrinkage of CA1 strata oriens, radiatum and lacunosum moleculare; and the proportional expansion ("cell spreading") of the dentate gyrus. Open rectangles denote the location of insets in $\boldsymbol{B}-\boldsymbol{B}_{\boldsymbol{1}}{ }^{\prime} . \boldsymbol{B}-\boldsymbol{B}_{\boldsymbol{1}}{ }^{\prime}$, Representative high-resolution photomicrographs depicting altered parvalbumin but unchanged VGLUT1 immunoreactivities in the strata oriens (or) and radiatum (rad) proximal to unstained pyramidal cells. C, Distribution plot along the anterior-posterior axis of the dorsal hippocampus. $\boldsymbol{C}_{1}$, Cumulative depiction of the extent of parvalbumin ${ }^{+}$ terminals and perikarya that had been spared after SAVA infusion. ${ }^{*} p<0.05$ vs the contralateral hemisphere. D, Box plot showing the width of the granule cell layer $\left.{ }^{* * *} p<0.001\right)$ used to quantify granule cell dispersion in control vs SAVA-treated hippocampi. Horizontal lines denote the $25^{\text {th }}, 50^{\text {th }}$ and $75^{\text {th }}$ percentiles, while error bars indicate the fifth and $95^{\text {th }}$ percentiles. $\boldsymbol{E}_{,} \boldsymbol{E}_{\boldsymbol{1}}$, The loss of $\mathrm{CB}_{1} \mathrm{R}^{+}$terminal fields of local-circuit interneurons emphasizes the SAVA-induced irreparable damage to the hippocampal circuitry. Pyramidal cell loss and the respective shrinkage of dendritic fields in the CA1 subfield are accompanied by the dispersion tion site. Nevertheless, SAVA exposure was well tolerated with $<14 \%$ premature mortality in both mice and rats. Since generalized epileptic seizures could not unequivocally be identified as the underlying cause of death, further studies addressing the safety of SAVA manipulations, as well as SAVA-induced behavioral impairments using long-term survival periods and complex measures of motor and cognitive functions are warranted.

We have established a lesion model that is sufficient to selectively immunolesion GABAergic interneurons, as supported by a coherent series of histochemical experiments at the light and electron microscopic levels, $\mathrm{Ca}^{2+}$ imaging, as well as electrophysiology performed in in vitro and in vivo experimental paradigms. We show that SAVAs are able to indiscriminately destroy GABAergic cells, as indicated by the concomitant loss of diverse subsets of hippocampal interneurons. The specificity of any lesion model toward a single cell type bears critical ramifications for its future exploitation in developmental neurobiology, cell biology, neuropharmacology or neuropathology. We present a convergent set of data highlighting GABAergic interneurons as SAVA's primary target. These include (1) the decreased frequency of mIPSCs before a marked impact on mEPSCs in vitro; and (2) the loss of $\mathrm{CB}_{1} \mathrm{R}$ and VGLUT3 immunoreactivities in GABAergic hippocampal afferents. The retained $\mathrm{CB}_{1} \mathrm{R}$ immunoreactivity of glutamatergic terminals in the dentate gyrus, and the unchanged distribution of VGLUT3 ${ }^{+}$ monoamine afferents at the stratum radiatum/lacunosum moleculare border (Somogyi et al., 2004) support SAVA's ability to selectively impair hippocampal GABA neurotransmission. In turn, we assign the increased $\mathrm{CB}$ immunoreactivity of CA1 pyramidal cells in SAVA-lesioned hippocampi (Fig. $5 A_{1}$ ) to compensatory changes aimed to counterbalance intracellular $\mathrm{Ca}^{2+}$ elevation arising from persistently increased excitation by glutamate.

SAVA-mediated removal of inhibitory components led to secondary modifications of electrical activity in excitatory neuronal networks in vitro. In particular, the increased frequency of mEPSCs and $\mathrm{Ca}^{2+}$ oscillations suggest the progressive

of granule cells ectopically expressing SAT1 in the dentate gyrus (DG). CA1-CA3, Cornu ammonis subfields; ctx, cortex; $g$, stratum granulare; Im, stratum lacunosum moleculare; $m$, stratum moleculare; pyr, stratum pyramidale; th, thalamus. Scale bars: $\boldsymbol{A}^{\prime}, \boldsymbol{A}_{1}^{\prime}, 250 \mu \mathrm{m} ; \boldsymbol{D}_{1} \boldsymbol{D}_{\mathbf{1}}, 150 \mu \mathrm{m} ; \boldsymbol{B}^{\prime}, 15 \mu \mathrm{m}$. 
enhancement of spontaneous excitatory network activity upon removal of the intrinsic GABA drive. In vivo, EEG recordings performed in freely moving mice revealed the incidence of highamplitude isolated spikes. Some of these high-amplitude discharges resembled interictal epileptiform events previously described in limbic networks in vitro (Traynelis and Dingledine, 1988; McNamara, 1994; McCormick and Contreras, 2001). We observed some baseline spiking in control mice. We attribute this finding to neuronal damage induced by the stereotaxic injection and implantation of deep bipolar electrodes. The robust difference in the frequency of epileptiform alterations between SAVAtreated and control groups emphasizes this neurotoxin's ability to impact hippocampal network activity. Yet these EEG data indicate a milder phenotype relative to other indiscriminate pharmacological treatments used to evoke severe epilepsy (Antonucci et al., 2008). The SAVA-induced loss of GABAergic interneurons likely precedes ultrastructural modifications reported during epilepsy (i.e., granule cell dispersion in dentate gyrus and glutamatergic neuronal loss), also inducing astro- and microgliosis (Haas et al., 2002; Riban et al., 2002; Vezzani et al., 2011). Although our data strongly suggest that SAVAs selectively compromise GABA neurons, we recognize that each prospective experimental system taking advantage of SAVA immunotoxins must strictly be controlled to avoid undesired side-effects of intraparenchymal SAVA infusion.

Overall, our data reinforce the largely unresolved notion that selective impairments to the inhibitory drive in hippocampal networks may act as a pathogenic trigger escalating excitotoxicity upon recurrent severe epilepsy. Our experimental findings also suggest that SAVA-induced GABA lesions in vitro and in vivo can recapitulate key molecular pathways underpinning synaptic pathomechanisms of neurological and psychiatric disorders severely affecting bodily or mental performance, including epilepsy, Parkinson's disease, autism, schizophrenia (Khazipov et al., 2001; Di Cristo, 2007; Murray et al., 2011), and be useful to explore novel pharmacotherapies aimed to combat these diseases.

\section{References}

Alpár A, Gärtner U, Seeger G, Härtig W, Brauer K, Arendt T (2004a) Constitutive expression of $\mathrm{p} 21 \mathrm{H}$-ras(Val12) in pyramidal neurons results in reorganization of mouse neocortical afferents. J Neurobiol 60:263-274.

Alpár A, Seeger G, Härtig W, Arendt T, Gärtner U (2004b) Adaptive morphological changes of neocortical interneurons in response to enlarged and more complex pyramidal cells in p21H-Ras(Val12) transgenic mice. Brain Res Bull 62:335-343.

Anderson SA, Kaznowski CE, Horn C, Rubenstein JL, McConnell SK (2002) Distinct origins of neocortical projection neurons and interneurons in vivo. Cereb Cortex 12:702-709.

Antonucci F, Di Garbo A, Novelli E, Manno I, Sartucci F, Bozzi Y, Caleo M (2008) Botulinum neurotoxin E (BoNT/E) reduces CA1 neuron loss and granule cell dispersion, with no effects on chronic seizures, in a mouse model of temporal lobe epilepsy. Exp Neurol 210:388-401.

Asada H, Kawamura Y, Maruyama K, Kume H, Ding RG, Kanbara N, Kuzume H, Sanbo M, Yagi T, Obata K (1997) Cleft palate and decreased brain gamma-aminobutyric acid in mice lacking the $67-\mathrm{kDa}$ isoform of glutamic acid decarboxylase. Proc Natl Acad Sci U S A 94:6496-6499.

Ascoli GA, Alonso-Nanclares L, Anderson SA, Barrionuevo G, BenavidesPiccione R, Burkhalter A, Buzsáki G, Cauli B, Defelipe J, Fairén A, Feldmeyer D, Fishell G, Fregnac Y, Freund TF, Gardner D, Gardner EP, Goldberg JH, Helmstaedter M, Hestrin S, Karube F, et al. (2008) Petilla terminology: nomenclature of features of GABAergic interneurons of the cerebral cortex. Petilla Interneuron Nomenclature Group. Nat Rev Neurosci 9:557-568.

Bacci A, Verderio C, Pravettoni E, Matteoli M (1999) Synaptic and intrinsic mechanisms shape synchronous oscillations in hippocampal neurons in culture. Eur J Neurosci 11:389-397.
Bacci A, Sancini G, Verderio C, Armano S, Pravettoni E, Fesce R, Franceschetti S, Matteoli M (2002) Block of glutamate-glutamine cycle between astrocytes and neurons inhibits epileptiform activity in hippocampus. J Neurophysiol 88:2302-2310.

Bartos M, Vida I, Jonas P (2007) Synaptic mechanisms of synchronized gamma oscillations in inhibitory interneuron networks. Nat Rev Neurosci 8:45-56.

Ben-Ari Y (2001) Cell death and synaptic reorganizations produced by seizures. Epilepsia 42 [Suppl 3]:5-7.

Ben-Ari Y (2002) Excitatory actions of gaba during development: the nature of the nurture. Nat Rev Neurosci 3:728-739.

Ben-Ari Y, Gaiarsa JL, Tyzio R, Khazipov R (2007) GABA: a pioneer transmitter that excites immature neurons and generates primitive oscillations. Physiol Rev 87:1215-1284.

Berger-Sweeney J, Heckers S, Mesulam MM, Wiley RG, Lappi DA, Sharma M (1994) Differential effects on spatial navigation of immunotoxininduced cholinergic lesions of the medial septal area and nucleus basalis magnocellularis. J Neurosci 14:4507-4519.

Boulland JL, Ferhat L, Tallak Solbu T, Ferrand N, Chaudhry FA, StormMathisen J, Esclapez M (2007) Changes in vesicular transporters for gamma-aminobutyric acid and glutamate reveal vulnerability and reorganization of hippocampal neurons following pilocarpine-induced seizures. J Comp Neurol 503:466-485.

Boyden ES, Zhang F, Bamberg E, Nagel G, Deisseroth K (2005) Millisecondtimescale, genetically targeted optical control of neural activity. Nat Neurosci 8:1263-1268.

Butuzova MV, Kitchigina VF (2008) Repeated blockade of GABAA receptors in the medial septal region induces epileptiform activity in the hippocampus. Neurosci Lett 434:133-138.

Buzsáki G, Kaila K, Raichle M (2007) Inhibition and brain work. Neuron 56:771-783.

Cardin JA, Carlén M, Meletis K, Knoblich U, Zhang F, Deisseroth K, Tsai LH, Moore CI (2009) Driving fast-spiking cells induces gamma rhythm and controls sensory responses. Nature 459:663-667.

Chaudhry FA, Reimer RJ, Bellocchio EE, Danbolt NC, Osen KK, Edwards RH, Storm-Mathisen J (1998) The vesicular GABA transporter, VGAT, localizes to synaptic vesicles in sets of glycinergic as well as GABAergic neurons. J Neurosci 18:9733-9750.

Cossart R, Bernard C, Ben-Ari Y (2005) Multiple facets of GABAergic neurons and synapses: multiple fates of GABA signalling in epilepsies. Trends Neurosci 28:108-115.

Costa E, Davis JM, Dong E, Grayson DR, Guidotti A, Tremolizzo L, Veldic M (2004) A GABAergic cortical deficit dominates schizophrenia pathophysiology. Crit Rev Neurobiol 16:1-23.

Davies P, Anderton B, Kirsch J, Konnerth A, Nitsch R, Sheetz M (1998) First one in, last one out: the role of gabaergic transmission in generation and degeneration. Prog Neurobiol 55:651-658.

Di Cristo G (2007) Development of cortical GABAergic circuits and its implications for neurodevelopmental disorders. Clin Genet 72:1-8.

Eytan D, Marom S (2006) Dynamics and effective topology underlying synchronization in networks of cortical neurons. J Neurosci 26:8465-8476.

Fattorini G, Verderio C, Melone M, Giovedi S, Benfenati F, Matteoli M, Conti F (2009) VGLUT1 and VGAT are sorted to the same population of synaptic vesicles in subsets of cortical axon terminals. J Neurochem 110:1538-1546.

Freund TF, Buzsáki G (1996) Interneurons of the hippocampus. Hippocampus 6:347-470.

Fritschy JM, Benke D, Mertens S, Oertel WH, Bachi T, Möhler H (1992) Five subtypes of type A gamma-aminobutyric acid receptors identified in neurons by double and triple immunofluorescence staining with subunitspecific antibodies. Proc Natl Acad Sci U S A 89:6726-6730.

Haas CA, Dudeck O, Kirsch M, Huszka C, Kann G, Pollak S, Zentner J, Frotscher M (2002) Role for reelin in the development of granule cell dispersion in temporal lobe epilepsy. J Neurosci 22:5797-5802.

Härtig W, Brückner G, Holzer M, Brauer K, Bigl V (1995) Digoxigenylated primary antibodies for sensitive dual-peroxidase labelling of neural markers. Histochem Cell Biol 104:467-472.

Heckers S, Ohtake T, Wiley RG, Lappi DA, Geula C, Mesulam MM (1994) Complete and selective cholinergic denervation of rat neocortex and hippocampus but not amygdala by an immunotoxin against the p75 NGF receptor. J Neurosci 14:1271-1289.

Hioki H, Fujiyama F, Nakamura K, Wu SX, Matsuda W, Kaneko T (2004) 
Chemically specific circuit composed of vesicular glutamate transporter 3- and preprotachykinin B-producing interneurons in the rat neocortex. Cereb Cortex 14:1266-1275.

Kaneko T, Fujiyama F, Hioki H (2002) Immunohistochemical localization of candidates for vesicular glutamate transporters in the rat brain. J Comp Neurol 444:39-62.

Katona I, Freund TF (2008) Endocannabinoid signaling as a synaptic circuit breaker in neurological disease. Nat Med 14:923-930.

Katona I, Sperlágh B, Sík A, Käfalvi A, Vizi ES, Mackie K, Freund TF (1999) Presynaptically located CB1 cannabinoid receptors regulate GABA release from axon terminals of specific hippocampal interneurons. J Neurosci 19:4544-4558.

Kawamura Y, Fukaya M, Maejima T, Yoshida T, Miura E, Watanabe M, Ohno-Shosaku T, Kano M (2006) The CB1 cannabinoid receptor is the major cannabinoid receptor at excitatory presynaptic sites in the hippocampus and cerebellum. J Neurosci 26:2991-3001.

Khazipov R, Esclapez M, Caillard O, Bernard C, Khalilov I, Tyzio R, Hirsch J, Dzhala V, Berger B, Ben-Ari Y (2001) Early development of neuronal activity in the primate hippocampus in utero. J Neurosci 21:9770-9781.

López-Bendito G, Cautinat A, Sánchez JA, Bielle F, Flames N, Garratt AN, Talmage DA, Role LW, Charnay P, Marín O, Garel S (2006) Tangential neuronal migration controls axon guidance: a role for neuregulin-1 in thalamocortical axon navigation. Cell 125:127-142.

Madsen KK, White HS, Schousboe A (2010) Neuronal and non-neuronal GABA transporters as targets for antiepileptic drugs. Pharmacol Ther 125:394-401.

Manent JB, Demarque M, Jorquera I, Pellegrino C, Ben-Ari Y, Aniksztejn L, Represa A (2005) A noncanonical release of GABA and glutamate modulates neuronal migration. J Neurosci 25:4755-4765.

Martens H, Weston MC, Boulland JL, Grønborg M, Grosche J, Kacza J, Hoffmann A, Matteoli M, Takamori S, Harkany T, Chaudhry FA, Rosenmund C, Erck C, Jahn R, Härtig W (2008) Unique luminal localization of VGAT-C terminus allows for selective labeling of active cortical GABAergic synapses. J Neurosci 28:13125-13131.

McBain CJ, Fisahn A (2001) Interneurons unbound. Nat Rev Neurosci 2:11-23.

McCormick DA, Contreras D (2001) On the cellular and network bases of epileptic seizures. Annu Rev Physiol 63:815-846.

McIntire SL, Reimer RJ, Schuske K, Edwards RH, Jorgensen EM (1997) Identification and characterization of the vesicular GABA transporter. Nature 389:870-876.

McNamara JO (1994) Cellular and molecular basis of epilepsy. J Neurosci 14:3413-3425.

Mody I, Otis TS, Staley KJ, Köhr G (1992) The balance between excitation and inhibition in dentate granule cells and its role in epilepsy. Epilepsy Res Suppl 9:331-339.

Monory K, Massa F, Egertová M, Eder M, Blaudzun H, Westenbroek R, Kelsch W, Jacob W, Marsch R, Ekker M, Long J, Rubenstein JL, Goebbels S, Nave KA, During M, Klugmann M, Wölfel B, Dodt HU, Zieglgänsberger W, Wotjak CT, et al. (2006) The endocannabinoid system controls key epileptogenic circuits in the hippocampus. Neuron 51:455-466.

Mulder J, Zilberter M, Pasquaré S, Alpár A, Schulte G, Ferreira SG, Köfalvi A, Martín-Moreno AAM, Keimpema E, Tanila H, Watanabe M, Mackie K, Hortobágyi T, de Ceballos MAL, Harkany T (2011) Molecular reorganization of endocannabinoid signalling in Alzheimer's disease. Brain 134:1041-1060.

Murray AJ, Sauer JF, Riedel G, McClure C, Ansel L, Cheyne L, Bartos M, Wisden W, Wulff P (2011) Parvalbumin-positive CA1 interneurons are required for spatial working but not for reference memory. Nat Neurosci 14:297-299.

Pang KC, Jiao X, Sinha S, Beck KD, Servatius RJ (2011) Damage of GABAergic neurons in the medial septum impairs spatial working memory and extinction of active avoidance: effects on proactive interference. Hippocampus 21:835-846.

Paxinos G, Franklin KBJ (2001) The mouse brain in stereotaxic coordinates. San Diego: Academic.

Paxinos G, Watson C (1986) The rat brain in stereotaxic coordinates. Boston: Academic.

Pitkänen A, Lukasiuk K (2009) Molecular and cellular basis of epileptogenesis in symptomatic epilepsy. Epilepsy Behav 14 [Suppl 1]:16-25.

Pitkänen A, Sutula TP (2002) Is epilepsy a progressive disorder? Prospects for new therapeutic approaches in temporal-lobe epilepsy. Lancet Neurol 1:173-181.

Pleasure SJ, Anderson S, Hevner R, Bagri A, Marin O, Lowenstein DH, Rubenstein JL (2000) Cell migration from the ganglionic eminences is required for the development of hippocampal GABAergic interneurons. Neuron 28:727-740.

Pozzi D, Condliffe S, Bozzi Y, Chikhladze M, Grumelli C, Proux-Gillardeaux V, Takahashi M, Franceschetti S, Verderio C, Matteoli M (2008) Activity-dependent phosphorylation of Ser 187 is required for SNAP-25negative modulation of neuronal voltage-gated calcium channels. Proc Natl Acad Sci U S A 105:323-328.

Radley JJ, Gosselink KL, Sawchenko PE (2009) A discrete GABAergic relay mediates medial prefrontal cortical inhibition of the neuroendocrine stress response. J Neurosci 29:7330-7340.

Riban V, Bouilleret V, Pham-Lê BT, Fritschy JM, Marescaux C, Depaulis A (2002) Evolution of hippocampal epileptic activity during the development of hippocampal sclerosis in a mouse model of temporal lobe epilepsy. Neuroscience 112:101-111.

Riedel A, Härtig W, Fritschy JM, Brückner G, Seifert U, Brauer K (1998) Comparison of the rat dorsal and ventral striatopallidal system. A study using the GABA(A)-receptor alphal-subunit and parvalbumin immunolabeling. Exp Brain Res 121:215-221.

Sagné C, El Mestikawy S, Isambert MF, Hamon M, Henry JP, Giros B, Gasnier B (1997) Cloning of a functional vesicular GABA and glycine transporter by screening of genome databases. FEBS Lett 417:177-183.

Santanché S, Bellelli A, Brunori M (1997) The unusual stability of saporin, a candidate for the synthesis of immunotoxins. Biochem Biophys Res Commun 234:129-132.

Sassoè-Pognetto M, Kirsch J, Grünert U, Greferath U, Fritschy JM, Möhler H, Betz H, Wässle H (1995) Colocalization of gephyrin and GABAAreceptor subunits in the rat retina. J Comp Neurol 357:1-14.

Schousboe A (2000) Pharmacological and functional characterization of astrocytic GABA transport: a short review. Neurochem Res 25:1241-1244.

Solbu TT, Bjørkmo M, Berghuis P, Harkany T, Chaudhry FA (2010) SAT1, A glutamine transporter, is preferentially expressed in GABAergic neurons. Front Neuroanat 4:1.

Somogyi J, Baude A, Omori Y, Shimizu H, El Mestikawy S, Fukaya M, Shigemoto R, Watanabe M, Somogyi P (2004) GABAergic basket cells expressing cholecystokinin contain vesicular glutamate transporter type 3 (VGLUT3) in their synaptic terminals in hippocampus and isocortex of the rat. Eur J Neurosci 19:552-569.

Somogyi P, Klausberger T (2005) Defined types of cortical interneurone structure space and spike timing in the hippocampus. J Physiol 562:9-26.

Stirpe F, Gasperi-Campani A, Barbieri L, Falasca A, Abbondanza A, Stevens WA (1983) Ribosome-inactivating proteins from the seeds of Saponaria officinalis L. (soapwort), of Agrostemma githago L. (corn cockle) and of Asparagus officinalis L. (asparagus), and from the latex of Hura crepitans $\mathrm{L}$. (sandbox tree). Biochem J 216:617-625.

Sturm MB, Tyler PC, Evans GB, Schramm VL (2009) Transition state analogues rescue ribosomes from saporin-L1 ribosome inactivating protein. Biochemistry 48:9941-9948.

Sun B, Halabisky B, Zhou Y, Palop JJ, Yu G, Mucke L, Gan L (2009) Imbalance between GABAergic and glutamatergic transmission impairs adult neurogenesis in an animal model of Alzheimer's disease. Cell Stem Cell 5:624-633.

Syrový I, Hodný Z (1991) Staining and quantification of proteins separated by polyacrylamide gel electrophoresis. J Chromatogr 569:175-196.

Traynelis SF, Dingledine R (1988) Potassium-induced spontaneous electrographic seizures in the rat hippocampal slice. J Neurophysiol 59:259-276.

Tricoire L, Pelkey KA, Erkkila BE, Jeffries BW, Yuan X, McBain CJ (2011) A blueprint for the spatiotemporal origins of mouse hippocampal interneuron diversity. J Neurosci 31:10948-10970.

Tsou K, Mackie K, Sañudo-Peña MC, Walker JM (1999) Cannabinoid CB1 receptors are localized primarily on cholecystokinin-containing GABAergic interneurons in the rat hippocampal formation. Neuroscience 93:969-975.

Turner DA, Buhl EH, Hailer NP, Nitsch R (1998) Morphological features of the entorhinal-hippocampal connection. Prog Neurobiol 55:537-562.

Verderio C, Matteoli M (2001) ATP mediates calcium signaling between astrocytes and microglial cells: modulation by IFN-gamma. J Immunol 166:6383-6391. 
Verderio C, Bruzzone S, Zocchi E, Fedele E, Schenk U, De Flora A, Matteoli M (2001) Evidence of a role for cyclic ADP-ribose in calcium signalling and neurotransmitter release in cultured astrocytes. J Neurochem 78:646-657.

Verderio C, Pozzi D, Pravettoni E, Inverardi F, Schenk U, Coco S, ProuxGillardeaux V, Galli T, Rossetto O, Frassoni C, Matteoli M (2004) SNAP-25 modulation of calcium dynamics underlies differences in GABAergic and glutamatergic responsiveness to depolarization. Neuron 41:599-610.

Vezzani A, French J, Bartfai T, Baram TZ (2011) The role of inflammation in epilepsy. Nat Rev Neurol 7:31-40.

Weiss MD, Derazi S, Rossignol C, Varoqui H, Erickson JD, Kilberg MS, Anderson KJ (2003) Ontogeny of the neutral amino acid transporter SAT1/ATA1 in rat brain. Brain Res Dev Brain Res 143:151-159.

Wiley RG (1992) Neural lesioning with ribosome-inactivating proteins: suicide transport and immunolesioning. Trends Neurosci 15:285290.

Wiley RG, Lappi DA (1997) Destruction of neurokinin-1 receptor expressing cells in vitro and in vivo using substance P-saporin in rats. Neurosci Lett 230:97-100.

Wiley RG, Berbos TG, Deckwerth TL, Johnson EM Jr, Lappi DA (1995) Destruction of the cholinergic basal forebrain using immunotoxin to rat NGF receptor: modeling the cholinergic degeneration of Alzheimer's disease. J Neurol Sci 128:157-166.

Wiley RG, Lemons LL, Kline RH 4th (2009) Neuropeptide Y receptorexpressing dorsal horn neurons: role in nocifensive reflex responses to heat and formalin. Neuroscience 161:139-147.

Wrenn CC, Picklo MJ, Lappi DA, Robertson D, Wiley RG (1996) Central noradrenergic lesioning using anti-DBH-saporin: anatomical findings. Brain Res 740:175-184 